\title{
Synaptic Circuitry of Physiologically Identified W-Cells in the Cat's Dorsal Lateral Geniculate Nucleus
}

\author{
Denis Raczkowski, ${ }^{1}$ James E. Hamos, ${ }^{2, a}$ and S. Murray Sherman ${ }^{2}$ \\ 'Department of Anatomy, Duke University Medical Center, Durham, North Carolina 27710, and ${ }^{2}$ Department of \\ Neurobiology and Behavior, State University of New York at Stony Brook, Stony Brook, New York 11794
}

The cat's retinogeniculocortical system is comprised of at least 3 parallel pathways, the $W$-, $X$-, and $Y$-cell pathways. Prior studies, particularly at the level of the lateral geniculate nucleus, have focused on $X$ - and $Y$-cells. In the present study, we describe the synaptic inputs for 2 geniculate $\mathbf{W}$-cells from the parvocellular $\mathbf{C}$-laminae after these neurons were physiologically identified and intracellularly labeled with HRP. For each of the W-cells, we examined electron micrographs taken from over $\mathbf{5 0 0}$ consecutive thin sections; we reconstructed the entire soma plus roughly $15 \%$ of the dendritic arbor and determined the pattern of synaptic inputs to these reconstructed regions of each neuron. In several ways, each $W$-cell exhibits a similar pattern of synaptic inputs. First, we estimate that each $W$-cell receives approximately 3000-4000 synaptic contacts, which occur most densely on dendrites 50-150 $\mu \mathrm{m}$ from each soma. Second, axosomatic contacts are extremely rare, and most derive from terminals with flattened or pleomorphic vesicles (F terminals). Third, terminals with round vesicles, large profiles, and pale mitochondria (RLP terminals), which are presumed to be retinal terminals, form only about $2-4 \%$ of all synapses onto these $W$-cells; these synapses occur on proximal dendrites. Fourth, F terminals, which provide roughly $15-20 \%$ of all synaptic input to these cells, occupy the same region of proximal dendritic arbor as do the RLP terminals. Fifth, and finally, terminals with round vesicles, small profiles, and dark mitochondria (RSD terminals) provide the majority of synapses along all portions of the dendritic arbor. Compared with geniculate $X$ - and $Y$-cells of the A-laminae (Wilson et al., 1984), these $W$-cells are innervated by fewer synapses overall and, in particular, by dramatically fewer synapses from RLP (or retinal) terminals. This paucity of direct retinal input to geniculate $W$-cells might explain the remarkably poor responsiveness of these neurons to visual stimuli and to electrical activation of the optic chiasm.

\footnotetext{
Received Aug. 19, 1986; revised July 7, 1987; accepted July 7, 1987.

This work was supported by NSF Grants BNS-84-10238 and BNS-85-19709 to D.R. and NIH Grants EY03038 and EY03604 to S.M.S. We thank Susan C. Van Horn for her fine technical skill in preparing the serial, ultrathin sections and for helping to develop the many micrographs. We are also grateful to Joan Sommermeyer and Angela Gero for their assistance.

Correspondence should be addressed to Dr. Denis Kaczkowski at the above address.

- Present address: Department of Neurology, University of Massachusetts Medical Center, 55 Lake Avenue North, Worcester, MA 01605.
}

Copyright $@ 1988$ Society for Neuroscience 0270-6474/88/010031-18\$02.00/0
The cat's retinogeniculocortical system is comprised of at least 3 parallel and independent pathways, the $\mathrm{W}-\mathrm{X} \mathrm{X}$ - and $\mathrm{Y}$-cell pathways. The constituent $\mathrm{X}$ - and $\mathrm{Y}$-cells have been the subject of most studies to date, and we thus know a great deal about their functional organization. In both the retina and lateral geniculate nucleus, $\mathrm{X}$ - and $\mathrm{Y}$-cells constitute fairly homogeneous neuronal classes, and they can be distinguished on the basis of a number of physiological and morphological criteria (for recent reviews, see Sherman and Spear, 1982; Rodieck and Brening, 1983; Stone, 1983; Sherman and Koch, 1986). The receptive field properties of a geniculate $\mathrm{X}$ - or $\mathrm{Y}$-cell closely matches that of its main retinal afferent input, since each of these geniculate neurons typically receives its excitatory retinal input from a single axon or a few axons of the same functional type (Cleland et al., 1971). Furthermore, preliminary information regarding the pattern of synaptic inputs onto geniculate $\mathrm{X}$ - and $\mathrm{Y}$-cells is now available (Wilson et al., 1984).

$\mathrm{W}$-cells, by contrast, have been distinguished from $\mathrm{X}$ - and Y-cells only relatively recently; considerably less is thus known about them, particularly at the level of the lateral geniculate nucleus. Geniculate W-cells have been studied most extensively in the parvocellular C-laminae, in which most or all neurons are now known to be W-cells (Cleland et al., 1975; Wilson et al., 1976; Sur and Sherman, 1982). Stanford et al. (1983) have shown that these W-cells are morphologically distinct from Xand $Y$-cells of the A-laminae. However, virtually nothing is known about the synaptic circuitry involved in the innervation of these geniculate W-cells, circuitry that might differ considerably from that known for X-and Y-cells. For instance, connectivity studies have shown that the geniculate A-laminae have sources of input that differ from those of the parvocellular C-laminae (Graybiel and Berson, 1980; Torrealba et al., 1981). Also, the extent to which the receptive field properties of these neurons match those of their retinal afferent inputs is unclear.

For these reasons, we initiated the present study in order to describe synaptic inputs onto individual $\mathrm{W}$-cells located in the parvocellular C-laminae. This was accomplished by combining intracellular labeling of physiologically identified W-cells with subsequent electron microscopic analysis of the labeled neurons. A comparison of these data with analogous data for $\mathrm{X}$ - and Y-cells (Wilson et al., 1984) reveals several differences among these neuronal classes. Most obvious among these is the relative paucity of retinal input to these W-cells, which might explain their poor responsiveness to retinal stimuli under our recording conditions. The pattern of nonretinal input to W-cells is fairly similar to that noted earlier for X-and Y-cells, although we cannot yet be certain of the sources of these nonretinal inputs. 
Finally, it is obvious that the distribution of terminal types is not uniform along the dendrites of these neurons. A preliminary report of some of these observations has appeared in abstract form (Raczkowski et al., 1984).

\section{Materials and Methods}

Since many of the procedures used in these experiments have been described in detail previously (Friedlander et al., 1981; Wilson et al., 1984), we provide only a brief outline here. We obtained the data for this study from 2 normal adult cats. The cats were anesthetized (initally with $4 \%$ halothane and a 1:1 mixture of nitrous oxide/oxygen and subsequently with a 70:30 mixture of nitrous oxide/oxygen supplemented with a $2 \mathrm{mg} / \mathrm{kg} / \mathrm{hr}$ intravenous infusion of sodium pentobarbital), placed in a stereotaxic apparatus, paralyzed, artificially ventilated, and prepared for visual neurophysiology. We dilated the animals' pupils, retracted their nictitating membranes, and fitted contact lenses to their corneas. The lenses were chosen by retinoscopy to focus the eyes on visual stimuli that consisted either of bright and dark targets presented on a plotting screen or of gratings sinusoidally modulated in space and time and presented on a cathode ray tube. Bipolar stimulating electrodes were placed across the optic chiasm.

We recorded single-unit activity with fine-tipped micropipettes filled with HRP. Neurons encountered in the lateral geniculate nucleus were classified extracellularly on the basis of a battery of tests, including the latency of orthodromic response from optic chiasm stimulation, the briskness of response to visual stimulation, receptive field size, ocular dominance, the polarity (on or off) of the receptive field center, and the linearity of spatial and temporal response summation to counterphased sine-wave gratings. The primary criteria for identifying a neuron as a W-cell were a long response latency to optic chiasm stimulation $(>2.0$ $\mathrm{msec}$ ), poor responses to visual stimulation, and inconsistent responses to sine-wave gratings (Cleland and Levick, 1974a, b; Cleland et al., 1975; Wilson et al., 1976; Sur and Sherman, 1982; Stanford et al., 1983) Following extracellular classification, we impaled the cell, confirmed that the impaled cell was the same neuron studied extracellularly, and iontophoresed HRP into the cell. We limited our injections to the parvocellular C-laminae.

Several hours following the intracellular injections, these animals were deeply anesthetized with a large intravenous dose of barbiturate (50 $\mathrm{mg} / \mathrm{kg}$ ) and perfused through the heart with fixative ( $1 \%$ paraformaldehyde and $2 \%$ glutaraldehyde in a $0.15 \mathrm{~m}$ phosphate buffer with calcium chloride) followed by a rinse (5\% dextrose in phosphate buffer). We removed the brains, blocked them down to pieces containing the lateral geniculate nucleus, and refrigerated these blocks overnight in a solution of $5 \%$ dextrose in phosphate buffer. On the following day, $50-\mu \mathrm{m}$-thick sections were cut in the coronal plane with a vibratome. They were then reacted with diaminobenzidine, and the reaction was intensified with cobaltous chloride (Adams, 1977). We wet-mounted the sections and examined them for the presence of HRP-injected neurons. Sections containing portions of these neurons were osmicated, dehydrated, and embedded in plastic resin sandwiched between 2 pieces of plastic. We examined these sections and traced the neurons at a magnification of $1000 \times$ with a Leitz light microscope equipped with a $100 \times$ oil-immersion objective (N.A. 1.32) and a drawing tube.

For 2 reasons, we selected the pair of W-cells described below for detailed electron microscopic analysis. First, each had a soma and an extensive portion of its dendritic arbor contained within a single 50$\mu \mathrm{m}$-thick block of tissue. Second, these cells were dissimilar in some morphological features, and they thus exhibited many of the heterogeneous morphological features seen among geniculate W-cells (Stanford et al., 1983; see also Discussion). Serial ultrathin sections were cut from each block (500-600 per series), mounted on single-hole, Formvarcoated grids, and stained with uranyl acetate and lead citrate. Finally, we examined the sections for terminals contacting labeled profiles with a Phillips 301 or a JEOL $100 \mathrm{~B}$ electron microscope.

The ultrastructural analysis of these W-cells was accomplished in 2 stages. First, we searched for HRP-labeled processes and photographed these processes through every other section of the series. We worked at a magnification of $2500 \times$ and produced micrographs with a final magnification of $8500 \times$. At this magnification, we could analyze a wide area of the section and, with the aid of $7 \times$ and $10 \times$ magnifying lenses placed over the micrographs, we could determine the morphological features of synaptic terminals and their contact zones. Second, the outlines of the HRP-filled processes were traced onto acetate sheets and manually aligned using internal fiducial points such as myelinated axons or blood vessels. Also indicated were the positions and identities of all terminals forming synapses.

The sections from which our reconstructions were made had a silvergold interference color, which implies an average thickness of $0.08 \mu \mathrm{m}$ (Peachey, 1958). For each neuron, we reconstructed virtually the entire soma and at least $15 \%$ of the dendritic lengths contained within each of the proximal, intermediate, and distal dendritic arbors. The actual length of every dendrite examined with the electron microscope was obtained from measurements taken directly from our electron microscopic reconstructions.

The remaining unexamined dendrites that comprise the arbors of these W-cells were measured from 2-dimensional drawings of the 3-dimensional arbors. Because the dendritic arbors of geniculatc W-cclls form a disc oriented parallel to the plane of the geniculate layers (Stanford et al., 1983; this was also clear in our material) and because our plane of section was nearly parallel to the short axis of these arbors, many of these unexamined dendritic lengths would be underestimated. Therefore, to obtain a measure of true dendritic length, we calculated a correction factor in the following manner. For disc-shaped arbors, the average angle out of the coronal plane of section of individual dendrites would be $45^{\circ}$. Since the sine of this angle (0.71) is the measured length on a 2 -dimensional drawing, this potentially introduces a $29 \%$ underestimation of true dendritic length. Therefore, we divided all measurements obtained from the 2-dimensional drawings by 0.71 to correct for this error. This is the same correction factor used by Wilson et al. (1984) in their analogous study of geniculate $\mathrm{X}$ - and $\mathrm{Y}$-cells, and the similarity of technique affords a more direct comparison between our W-cell data and these prior observations of X-and Y-cells. Finally, we determined the distance between the dendritic location of each synapse and the center of the soma, and this allowed us to calculate the percentage of synapses from each terminal variety as a function of distance from the soma.

Unless otherwise indicated, we employed the Mann-Whitney $U$ test for all statistical comparisons.

\section{Results}

\section{Electrophysiological properties}

We morphologically analyzed 2 geniculate $W$-cells that were physiologically identified on the basis of a battery of tests (see Table 1). We refer to these cells as W-a and W-b. Each neuron responded reliably to optic chiasm stimulation with a latency greater than $2.5 \mathrm{mscc}$. They exhibited receptive fields with an antagonistic, center-surround receptive field organization, had similar receptive field center sizes and comparable eccentricities from the area centralis, and responded in a phasic manner to stimuli of the appropriate standing contrast. One of these cells (W-a) had an on-center receptive field and exhibited linear spatial and temporal summation. The other (W-b) had an off-center receptive field and only intermittently responded to the grating stimuli. Cell W-b could not be reliably assessed in terms of spatial and temporal summation properties; however, when evoked, its responses were always linear.

\section{Light microscopic observations}

Light microscopic tracings of cells $\mathbf{W}-\mathbf{a}$ and $\mathrm{W}-\mathrm{b}$ are shown in Figure 1. Both somata are located in the parvocellular C-laminae, although the precise location of these neurons with respect to specific C-laminae is unclear from our histological data. Identifying such a relationship requires a means of delineating the retinal input from each eye (Hickey and Guillery, 1974). However, given their ocular dominance, it is likely that the soma of cell $\mathrm{W}$-a is located in lamina $\mathrm{Cl}$ and that the soma of cell $\mathrm{W}-\mathrm{b}$ lies in lamina $\mathrm{C} 2$.

These geniculate W-cells not only are morphologically distinct from geniculate X- and Y-cells (Friedlander et al., 1981; Stanford et al., 1983), but they also share certain structural features with one another. Relative to other geniculate cells in the A- 


\section{A.}
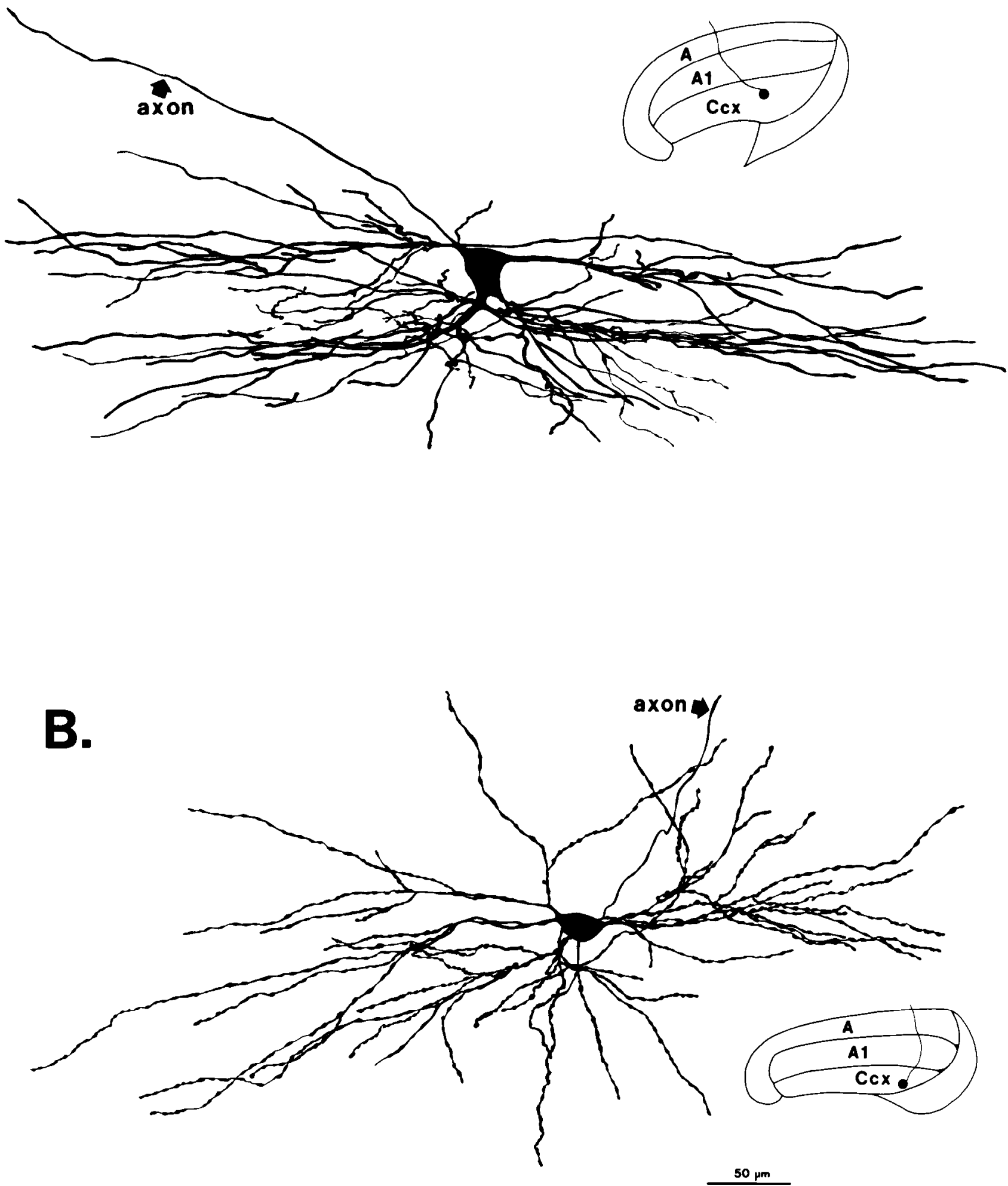

Figure 1. Tracings of 2 geniculate W-cells, W-a $(A)$ and W-b $(B)$, located in the C-laminae $(C c x)$. The cells were intracellularly filled with HRP and reconstructed from adjacent 50- $\mu \mathrm{m}$-thick coronal sections. Each neuron has a small to medium-sized soma, numerous dendritic varicosities, and few dendritic appendages. Inset drawings indicate the position of the soma and the course of the axon relative to laminar borders. Scale bar refers to the main drawings. 
Figure 2. Electron micrograph of representative terminals in the cat's lateral geniculate nucleus contacting dendrites $(d e n)$ and appendages (app). In this and subsequent micrographs, synaptic sites are indicated by arrowheads directed towards the postsynaptic side of the synapse.

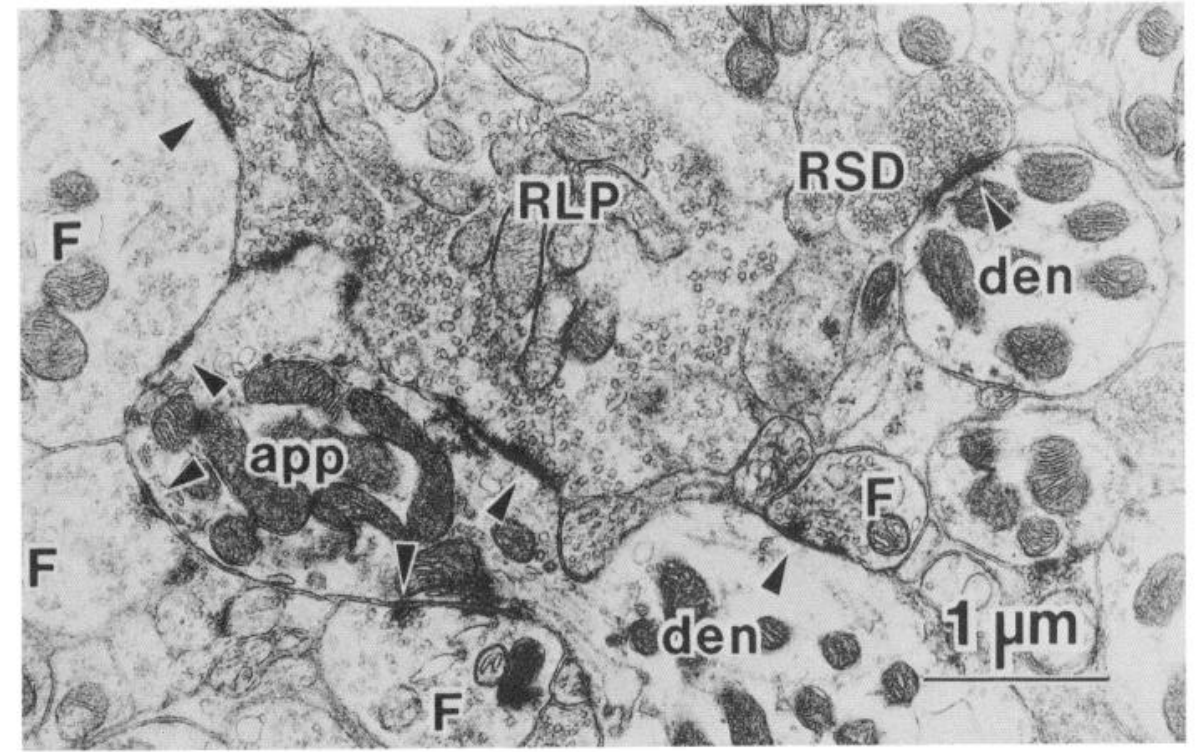

and C-laminae, both labeled cells have small to medium somata. Their dendritic arbors are oriented parallel to the borders of geniculate laminae and are comprised of fine, fairly smooth dendrites bearing rare spinelike appendages. Both neurons possess primary dendrites that are relatively straight and secondary dendrites that are more variable in appearance. Many of the latter exhibit alternate swellings and constrictions. Depending on the degree of these constrictions, secondary dendrites take on a varicose (cell W-a) or beaded (cell W-b) appearance.

\section{Electron microscopic observations}

\section{Identification of synaptic inputs}

Terminals forming synapses on the labeled W-cells can be recognized by their characteristic morphology. We adopted Guillery's (1969a) classification scheme and nomenclature that was originally developed for the A-laminae of the lateral geniculate nucleus and subsequently extended to the C-laminae (Guillery, 1969a; Guillery and Scott, 1971; Mize et al., 1986). Figure 2 provides examples of the various synaptic terminal types. RLP terminals have round vesicles, are relatively large, and contain pale mitochondria. All RLP terminals form asymmetrical synapses and arise from the axons of retinal ganglion cells (Guillery, 1969a; Robson and Mason, 1979; Mize et al., 1986). F terminals are distinguished by flattened or pleomorphic vesicles and form symmetrical synapses. In the A-laminae, F terminals have been further subdivided into 2 types based on certain ultrastructural

Table 1. Physiological properties

\begin{tabular}{lll} 
& W-a & W-b \\
\hline Optic chiasm latency $(\mathrm{msec})$ & 5.5 & 2.8 \\
Center type & On & Off \\
Receptive-field center size $(\mathrm{deg})$ & 2.0 & 1.5 \\
Receptive-field eccentricity $(\mathrm{deg})$ & 3.0 & 2.0 \\
Dominant eye & Ipsilateral & Contralateral \\
Phasic or tonic & Phasic & Phasic \\
Linear or nonlinear & Linear & $a$
\end{tabular}

${ }^{a}$ Response too inconsistent to evaluate. features (Guillery, 1969a, 1971; Famiglietti and Peters, 1972). Unfortunately, the distinguishing features needed to identify the 2 types of $\mathrm{F}$ terminals are not always evident in our material, and thus we have generally treated all terminals that contain flattened synaptic vesicles as belonging to a single class (but see below). RSD terminals possess round vesicles, are relatively $s$ mall, and sometimes contain dark mitochondria. All RSD terminals form asymmetrical synapses, and many in the A-laminae arise from corticogeniculate axons (Robson, 1983), although other sources may exist for many RSD terminals in the parvocellular C-laminae (see Discussion).

Recently, a fourth terminal type has been described for the perigeniculate nucleus (Ide, 1982), which lies just dorsal to lamina $\mathrm{A}$. This terminal variety, which occurs rarely in the A-laminae (Famiglietti and Peters, 1972; Hamos et al., 1985), has been termed the RLD terminal for its round vesicles, large profiles, and dark mitochondria. We found no synapses from RLD terminals on either of the labeled W-cells, and we shall not discuss this terminal type further.

In order to identify terminal varieties that form synapses in our experimental material, we relied primarily on morphological differences within the terminal itself, because symmetry of the synaptic contact is often obscured by the HRP reaction product contained in the postsynaptic W-cells. Furthermore, the identification of a synaptic contact zone is clearly more difficult when the postsynaptic processes are filled with HRP. Ideally, one would count as a synaptic site a region for which the presynaptic profile contains clustered synaptic vesicles and for which the parallel pre- and postsynaptic membranes display obvious thickenings on either side of a widened synaptic cleft (cf. Fig. 2). However, since postsynaptic thickenings often are obscured by the HRP reaction product, we relied on the presence of vesicles clustered along a presynaptic density and a widened synaptic cleft to determine that a synapse was being made onto the HRP-filled process. This determination usually was made over a number of serial sections in order to minimize errors caused either by counting a synapse where none exists (e.g., at a location where vesicles appear to be clustered but no synaptic cleft is present) or by missing a synapse (e.g., at a location where vesicle clustering is not obvious but where the synaptic cleft is 


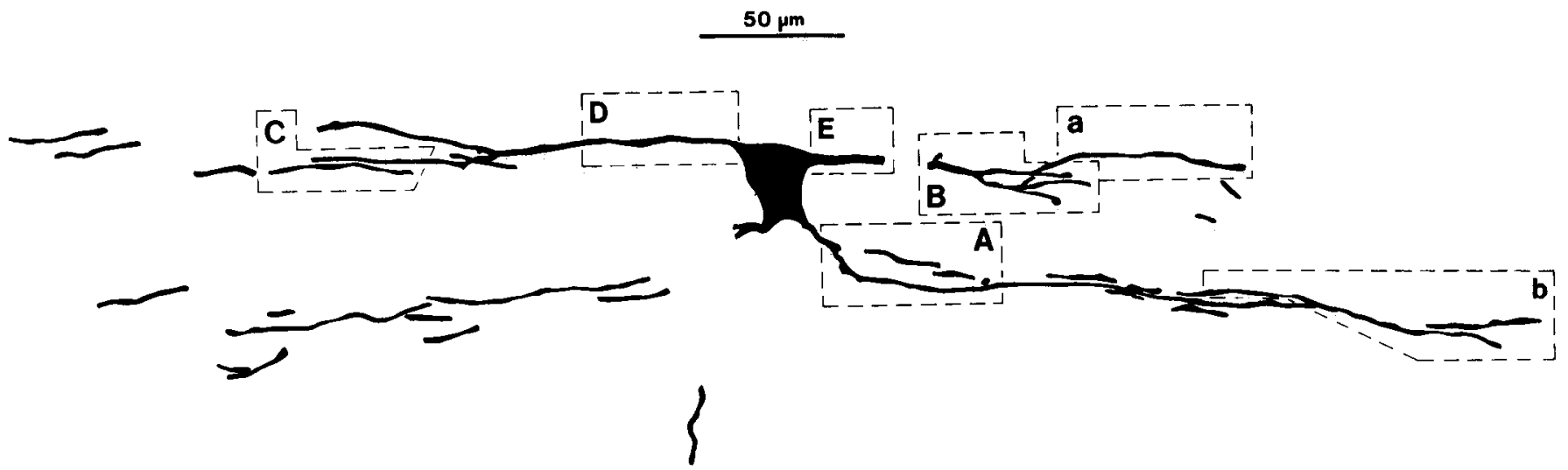

Figure 3. Tracing of those portions of one geniculate W-cell (W-a) that were thin-sectioned, examined with the electron microscope, and reconstructed with their synaptic inputs. The regions enclosed by dashed lines and labeled $A-E$ refer to those dendritic segments from this cell that are postsynaptic to RLP or retinal terminals. These dendritic segments arc illustrated with their synaptic inputs in Figure 9. The regions labelcd $a$ and $b$ are shown with their synaptic inputs in Figure 12. Note that all regions outside the dashed lines were also reconstructed, even though they are not further illustrated.

clearly widened). While limited, these procedures represent the same set of criteria for identifying terminal varieties and synaptic sites as used in analogous studies of geniculate $\mathrm{X}$ - and Y-cell in the A-laminae (Wilson et al., 1984; Hamos et al., 1985).

\section{Distribution and number of afferent inputs}

We used the following approach to determine the distribution and number of synapses contacting the labeled W-cells. We reconstructed with the electron microscope all of those portions of the $2 \mathrm{~W}$-cells illustrated in Figures 3 and 4, together with their synaptic inputs. Dashed lines enclose portions of the cells that are highlighted in subsequent illustrations. The locations of synapses on the somata and dendrites were determined by correlating the distances measured on the electron microscopic reconstructions with those from the light microscopic drawings. On our drawings of the cells, we centered around the soma a series of concentric circles $50 \mu \mathrm{m}$ apart. Within every $50-\mu \mathrm{m}$ wide annulus thus created, we then measured the lengths of all dendrites examined with the electron microscope, and we estimatcd the true lengths of all other dendrites from the 2-dimensional drawings of the cells (see Materials and Methods).These measurements, which are provided in Table 2, indicate that we examined with the electron microscope and reconstructed virtually the entire soma and at least $15 \%$ of the proximal, intermediate, and distal zones of the dendritic arbor for each W-cell (see Materials and Methods).

With this systematic approach, we counted 792 synapses on cell W-a and 475 on cell W-b, specified the terminal type of

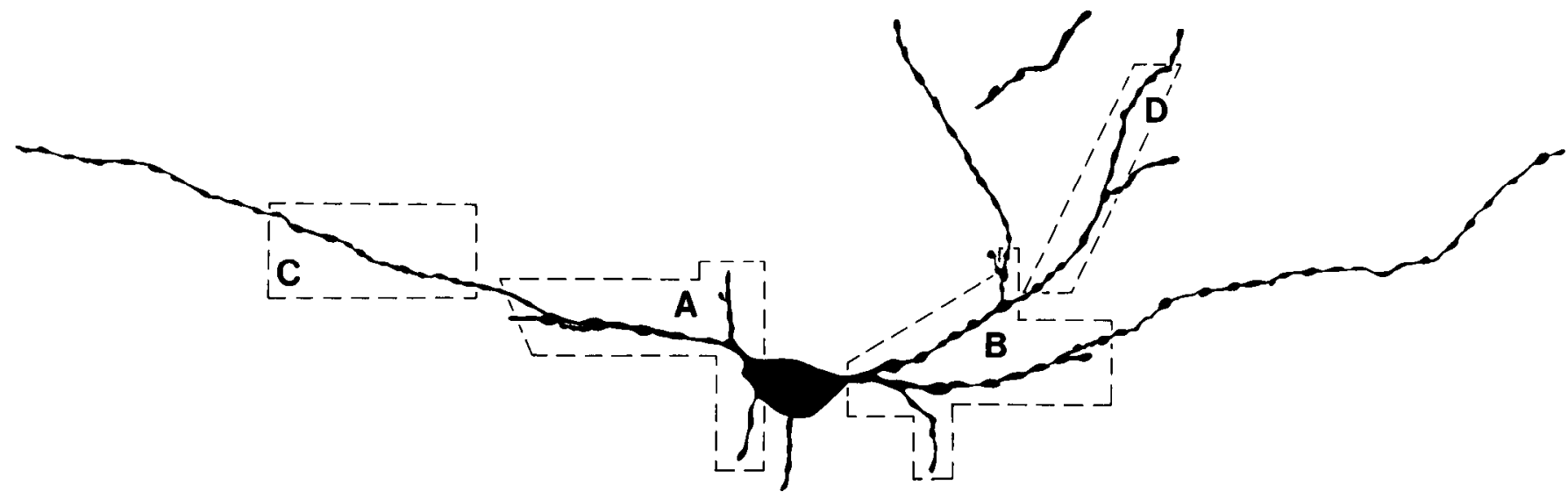

Figure 4. Tracing of those portions of another geniculate W-cell (W-b) that were thin-sectioned, examined with the electron microscope, and reconstructed with their synaptic inputs. The regions enclosed by dashed lines and labeled $A-D$ refer to those dendrites from this cell that are postsynaptic to RLP or retinal terminals. These dendritic segments are illustrated with their synaptic inputs in Figure 10. Note that all regions outside the dashed lines were also reconstructed, even though they are not further illustrated. 

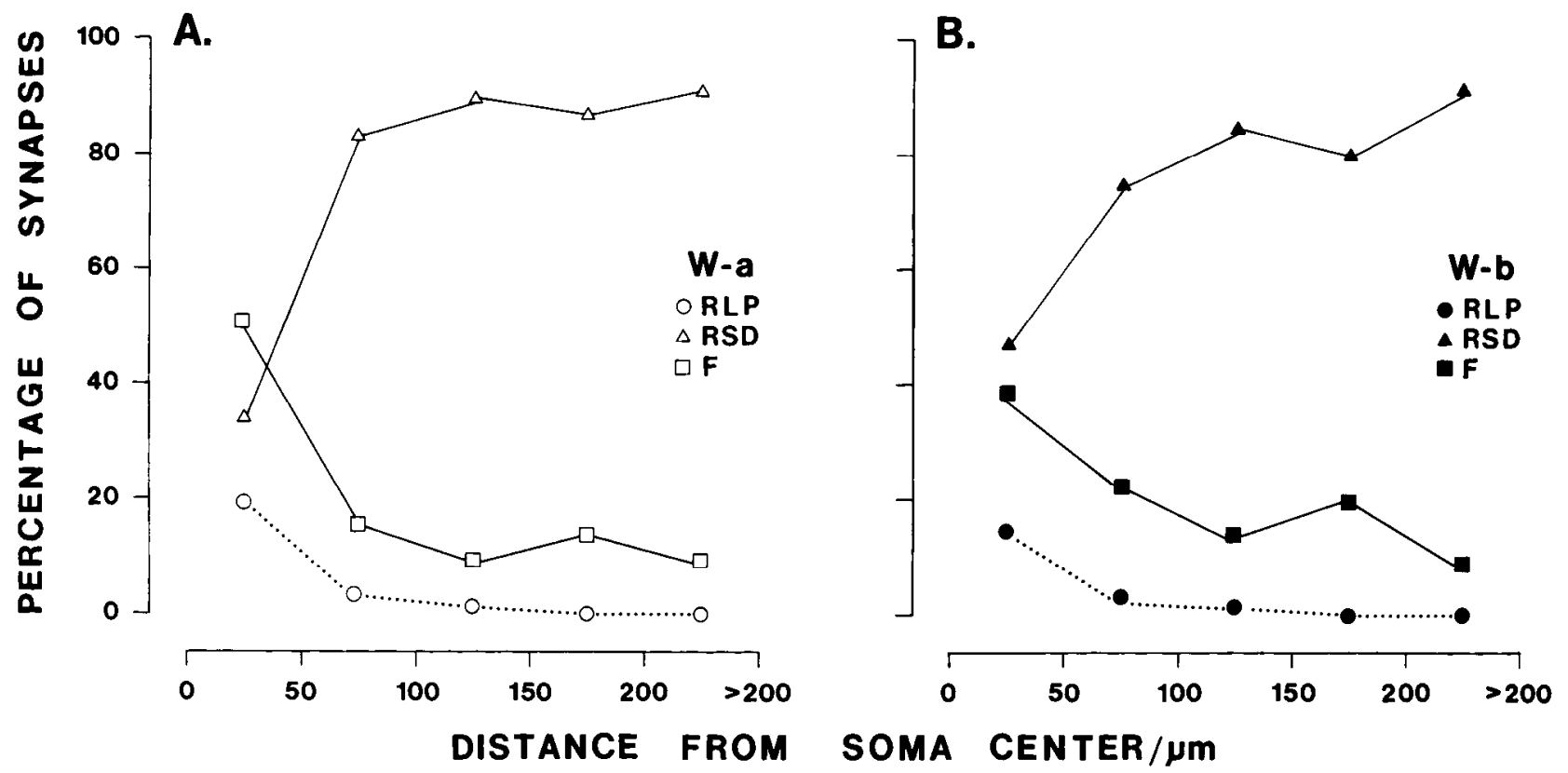

Figure 5. Graphs of the percentage of synapses from each terminal type along the dendrites of the 2 cells studied as a function of distance from their somata. The ordinate values were obtained by dividing the actual number of synapses from each terminal type by the total actual number of synapses in each $50 \mu \mathrm{m}$ annulus taken from Table 3.

origin, and indicated the location and percentage of each synaptic type at various distances away from the center of the soma (Fig. 5 and Table 3). This was the principal aim of the study. As a secondary aim, we used these data to extrapolate estimates of the total number, density, and distribution of terminals making synapses onto the entire dendritic arbors of these cells. This was accomplished by using a multiplication factor derived by dividing the total dendritic length in each zone by the length actually examined. In the following account, the real synaptic counts and the extrapolated calculations are described separately.

\section{Synapses on the somata of $W$-cells}

Very few synaptic contacts are formed directly on the somata of the labeled W-cells (Figs. 6, 7). Only 3 synapses contact the soma of cell $W$-a, 2 from $F$ terminals and 1 from an RSD terminal. Cell $\mathrm{W}$-b receives 16 synapses on its soma, 11 from $F$ terminals, and 5 from RSD terminals. We found no RLP terminal contacting either soma.

\section{Synapses on selected dendritic segments of $2 \mathrm{~W}$-cells}

Dendrites receive the vast majority of the synaptic input to the labeled W-cells. The differential distribution of synaptic con-

\section{Table 2. Dendritic lengths}

\begin{tabular}{crrrrrr}
\multicolumn{7}{c}{ Distance from soma center $(\mu \mathrm{m})$} \\
\cline { 2 - 7 } & $0-50$ & $51-100$ & $101-150$ & $151-200$ & $>200$ & Total \\
\hline Examined & & & & & & \\
W-a & 193 & 440 & 419 & 535 & 263 & 1850 \\
W-b & 241 & 351 & 345 & 128 & 85 & 1150 \\
Total & & & & & & \\
W-a & 932 & 2241 & 2067 & 3343 & 1016 & 9599 \\
W-b & 1076 & 2301 & 2278 & 898 & 501 & 7054 \\
\hline
\end{tabular}

tacts from different terminal types along different dendritic regions suggests that the dendritic arbors of geniculate W-cells can be divided into at least 2 distinct functional zones. A proximal zone nearer the soma $(0-150 \mu \mathrm{m})$ contains practically all of the synapses from RLP and F terminals, plus numerous inputs from RSD terminals. A distal zone farther from the soma ( $>150$ $\mu \mathrm{m})$ contains synapses nearly exclusively from RSD terminals. Thus, RLP and F terminals contact the proximal portions of the dendritic arbor, while RSD terminals contact both the proximal and distal portions of the dendritic arbor.

Synapses from RLP terminals. RLP terminals provide synapses only to the dendrites of these W-cells; these synapses are relatively frequent near the soma but become rare at increasing distances along the dendritic arbor. No RLP terminals form synapses beyond $150 \mu \mathrm{m}$ from the center of the soma (Fig. 5, Table 3). Although we examined and serially reconstructed the entire arbors illustrated in Figures 3 and 4, only those segments enclosed in boxes designated by an upper-case letter are contacted by RLP terminals. Figure 8 illustrates typical synapses from RLP terminals in our material. The serial reconstructions of these retinorecipient dendritic segments, complete with synaptic contacts, are illustrated in Figures 9 and 10.

These reconstructions make several additional points about the retinogeniculate circuitry of these W-cells. First, the retinal input is discontinuous; clearly some dendrites receive clusters of retinal input over a membrane length of about $5 \mu \mathrm{m}$ (Figs. $8 A ; 9 A ; 10, A, B)$, while other dendritic lengths are very sparsely contacted (cf. Figs. 9, 10). Second, most of these RLP terminals are small and make simple axodendritic contacts onto these W-cells (Figs. 8-10). As noted in the light microscope, very few appendages are present on these W-cells, and those appendages identified in the electron microscope do not receive inputs from RLP terminals (e.g., Fig. 10A, asterisk). Third, few RLP terminals are involved in synaptic triads, which are common for $\mathrm{X}$-cells in the A-laminae. These triads are arrangements of synapses that include a presynaptic RLP terminal providing syn- 
Table 3. Actual synaptic counts for neurons $W$-a and W-b

\begin{tabular}{ccccccc}
\multicolumn{7}{c}{ Distance from soma center $(\mu \mathrm{m})$} \\
\cline { 2 - 7 } RLP & $0-50$ & $51-100$ & $101-150$ & $151-200$ & $>200$ & Total \\
W-a & 10 & 5 & 3 & 0 & 0 & 18 \\
W-b & 12 & 6 & 2 & 0 & 0 & 20 \\
F & & & & & & \\
W-a & 27 & 32 & 22 & 26 & 13 & 120 \\
W-b & 32 & 47 & 18 & 6 & 2 & 105 \\
RSD & & & & & & \\
W-a & 16 & 153 & 209 & 150 & 126 & 654 \\
W-b & 39 & 154 & 112 & 24 & 21 & 350 \\
\hline
\end{tabular}

apses both to an $\mathrm{F}$ terminal and to a dendrite, with the $\mathrm{F}$ terminal also contacting the same dendrite (Guillery, 1969a; Famiglietti and Peters, 1972). Of the 18 identified synapses from retinal terminals innervating cell $\mathrm{W}-\mathrm{a}, 2$ formed part of a triad; of the 20 innervating cell W-b, only 1 RLP terminal was involved in a triad. One representative triad, seen in a single section, is illustrated in Figure $8 B$. These triads on W-cells are relatively simple arrangements of synapses that include only the postsynaptic dendrite and its presynaptic inputs. This contrasts with more complex encapsulated synaptic zones (i.e., glomeruli) observed in the A-laminae of the cat's lateral geniculate nucleus that include the components of triads, as well as other synapses (Guillery, 1969a; Famiglietti and Peters, 1972), and that are particularly associated with X-cells (Wilson et al., 1984; Hamos et al., 1985, 1987).

Synapses from $F$ terminals. Although synapses from $\mathrm{F}$ terminals can be found all along the dendritic arbor of the labeled W-cells, they tend to concentrate on proximal dendrites amid synapses from RLP terminals (see Fig. 5, Table 3). Indeed, more than $70 \%$ of the synapses from $\mathrm{F}$ terminals onto each $\mathrm{W}$-cell are found within the region of retinal input, defined as that part of the dendritic arbor within $150 \mu \mathrm{m}$ of the center of the soma. However, within the retinorecepient zone, synapses from $\mathrm{F}$ terminals outnumber those from RLP terminals by at least 4 to 1 . As noted above, only 3 of these $F$ terminals receive synapses from retinal terminals and participate in triads (Fig. $8 B$ ). These $3 \mathrm{~F}$ terminals share the same morphological features (pleomorphic vesicles residing in a light cytoplasmic matrix) as do F2 terminals participating in triadic arrangements in the A-laminae. Although we did not quantify the different populations of $\mathrm{F}$ terminals, the majority of the $\mathrm{F}$ terminals on these W-cells not participating in synaptic triads have a darker cytoplasmic matrix and more flattened vesicles that fill the profile. These features are reminiscent of Fl terminals observed in the A-laminae (Guillery, 1969a; Wilson et al., 1984).

Synapses from RSD terminals. RSD terminals provide the majority of synapses to the dendritic shafts of the $2 \mathrm{~W}$-cells (Figs. 5, 11, 12, Table 3). With the exception of the dendritic arbor closest to the soma of cell W-a, the number of RSD synapses is greater than any other type at all distances from each soma (Fig. 5). Furthermore, except for the most proximal part of the dendritic arbor, synapses from RSD terminals also outnumber the total from RLP and F terminals, often by a 3-fold margin or better. Since the distribution of RSD terminals contacting the proximal and distal dendrites of these cells is similar
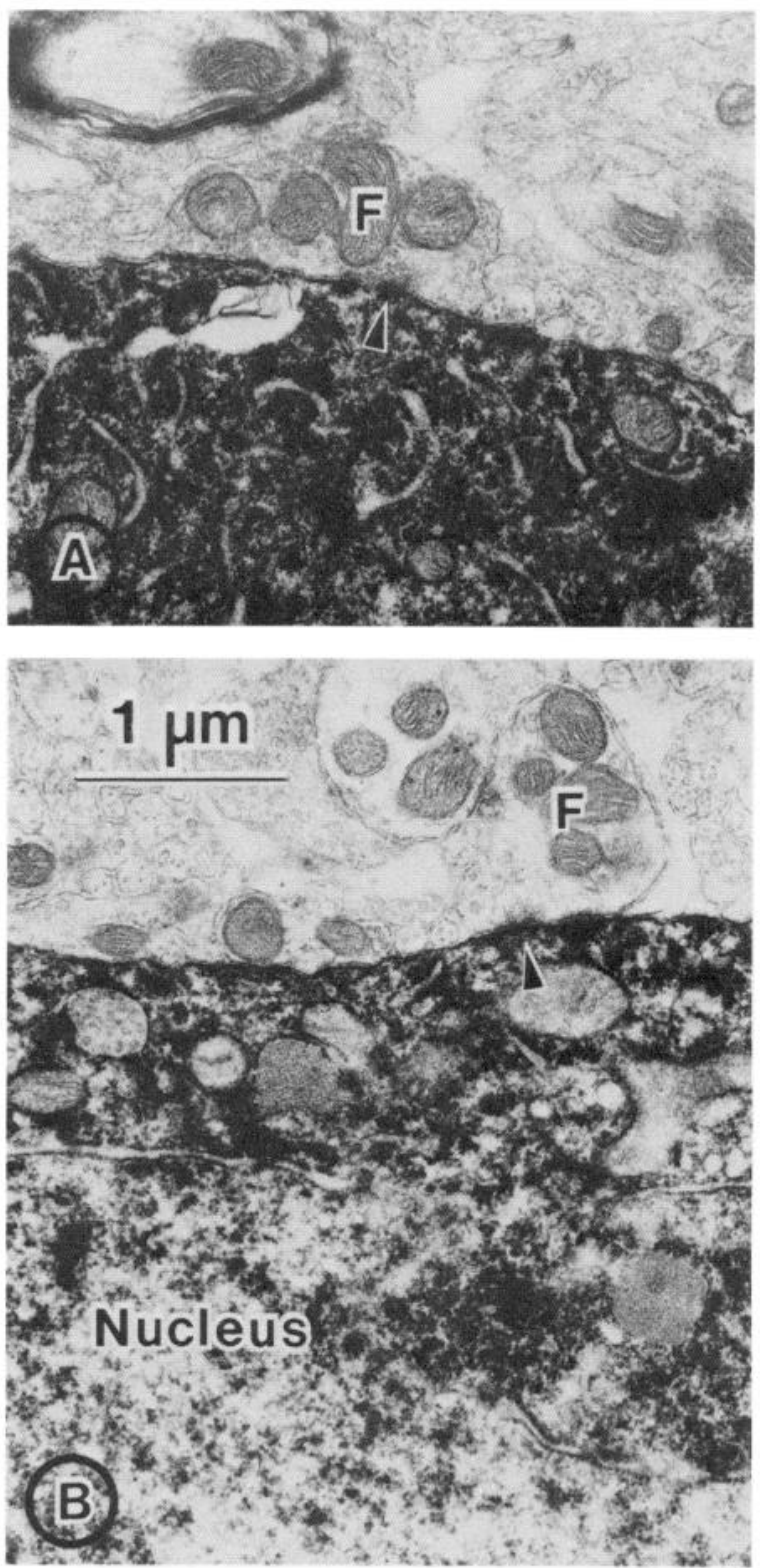

Figure 6. Electron micrographs of $\mathrm{F}$ terminals forming synapses (arrowheads) on the soma of cell W-a.

(Fig. 5) and since we have already provided reconstructions of proximal dendrites from both cells (see Figs. 9, 10), we show only additional reconstructions of representative distal dendrites from cell W-a (Fig. 12). It is interesting to note that despite their numerical superiority at all distances from the soma, RSD contacts occasionally are separated by many micrometers. Indeed, we routinely found dendritic segments of 5-10 micrometers devoid of any synaptic input (cf. Figs. 9-12).

\section{Estimated synapses on the entire dendritic arbor of $2 \mathrm{~W}$-cells}

Figure 13 shows the total estimated number of synapses from RLP, F, and RSD terminals made onto the dendritic arbors of these $2 \mathrm{~W}$-cells at increasing distances from the center of the soma. To extrapolate these estimates, we multiplied the actual counts from Table 3 by the appropriate multiplication factor derived by dividing the total dendritic length in each annulus by the examined dendritic length. In extrapolating from real 

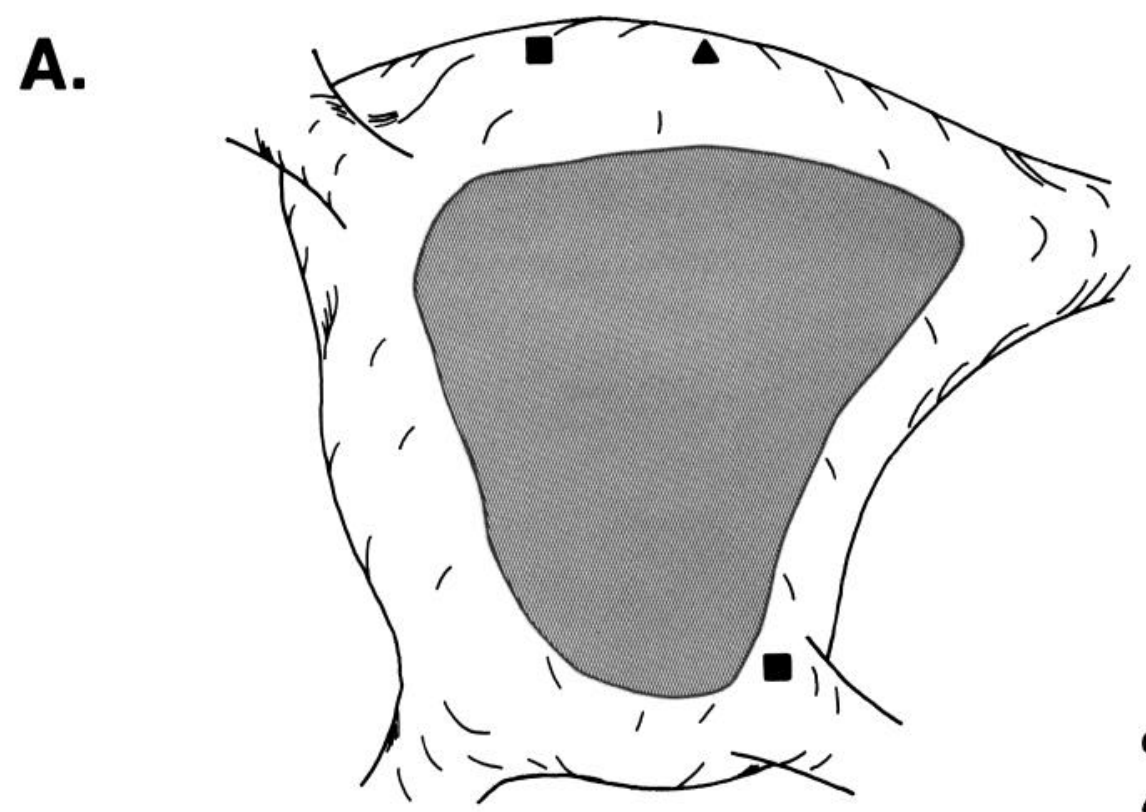

RLP

$\triangle$ RSD

- $F$

Figure 7. Reconstructions of the somata of 2 HRP-filled W-cells (W-a and W-b) showing the distribution and types of terminals making synaptic contacts. In this and similar figures that follow, each synapse from a different terminal is represented by a different symbol. $A$, Soma of $\mathrm{W}$-a receives 2 synapses from $\mathrm{F}$ terminals (filled squares) and 1 from an RSD terminal (filled triangle). The shaded region represents a small portion of this soma that lies in an adjacent tissue block and that was not reconstructed. $B$, Soma of $\mathrm{W}-\mathrm{b}$ receives 16 synaptic contacts, of which 11 are from $\mathrm{F}$ terminals and 5 are from RSD terminals.
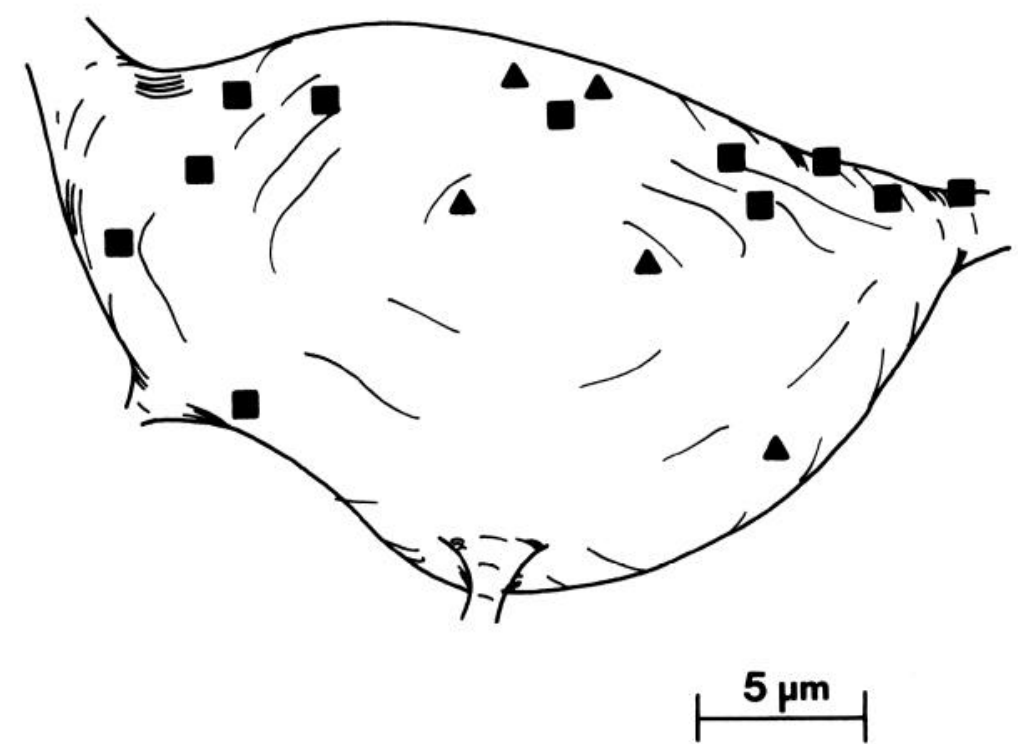

synaptic counts to presumed synaptic counts, we assume that other corresponding but unsampled dendritic segments have similar distributions of synapses. Two observations support this assumption: The patterns of synaptic input are remarkably similar for these $2 \mathrm{~W}$-cells, and these patterns closely match previous estimates of relative numbers of the different terminal types within the neuropil of the C-laminae (Guillery, 1969b; Guillery and Scott, 1971).

Based on these calculations, several conclusions can be drawn. First, the total estimated number of synapses made onto each neuron is similar; cell $\mathrm{W}$-a receives about 4000 total synapses, and cell $\mathrm{W}-\mathrm{b}$ receives about 3000 . Second, the total estimated number of retinal synapses made onto each neuron is quite similar (roughly 90 for cell W-a versus roughly 100 for cell W-b). Third, although RSD terminals are common at every distance from the soma, they are especially numerous on the proximal dendrites.

\section{Estimated density of synapses}

For each of the W-cells, Figure 14 shows the estimated density of synapses from each terminal type as a function of distance from the soma. The average synaptic density along the dendrites is roughly $0.4 / \mu \mathrm{m}$ for each cell. Synaptic density peaks in a region of intermediate distance (50-150 $\mu \mathrm{m})$ from the somata, mostly reflecting the high density of synapses from RSD terminals in these regions. 


\section{Relationship of anatomical and electrotonic distances}

In the above paragraphs, we have noted the anatomical location of synapses along dendrites and the distances separating these synapses from the soma. While this is one means of describing the pattern of synaptic inputs, it might be better on functional grounds to relate these observations to electrotonic distances that, in turn, relate to the efficacy of each synapse in terms of activating the neurons. We thus used the same algorithm as used by Hamos et al. (1987) to convert these anatomical distances to electrotonic ones. This involves the solution of simple cable equations (Jack et al., 1975) based on our electron microscopic measures of the length and thickness of various dendritic segments. We assume a passive membrane, negligible internal and external resistances, and constant internal and specific membrane resistances so that all measures, other than length and thickness, become constants. We divided the dendrites into nontapering segments so that each segment becomes a cylindrical cable. We then divided the length of each segment by the square root of its diameter (Rall, 1977). The relative electrotonic distance of each synapse from the soma is simply the sum of all of the electrotonic distances from the segments on a direct path from the synapse to the soma. We use a relative measure for electrotonic distance, because an absolute measure requires knowledge of various parameters, such as specific membrane resistance, that is unavailable to us.

Figure 15 shows the derived relationship between estimated anatomical and electrotonic distances for the 42 representative synapses sampled from these W-cells, 21 (7 of each terminal variety) from each cell. A very high correlation exists between these measures $(r>0.99$ and $p<0.001)$ for the entire sample and for each subset of 21 synapses from each W-cell. A similar close correlation between anatomical and electrotonic measures of distance was noted by Hamos et al. (1987) for 4 neurons postsynaptic to a retinogeniculate $\mathrm{X}$-axon in lamina $\mathrm{A}$. The correlation for our W-cells implies that the data summarized in Figures 5, 13, and 14, which represent anatomical distances between the synapses and soma for each cell, also reflect relative electrotonic distances. From these estimates of electrotonic distances, it is possible to deduce a first approximation of the relative efficacy of each synapse, although many unknowns (e.g., nonlinear behavior of the postsynaptic membranes, differential sensitivity to various transmitters, and presynaptic differences in transmitter release) preclude a detailed understanding of relative synaptic efficacy from our data.

Finally, since there is now evidence that the dendritic branching of relay X-and $\mathrm{Y}$-cells of the A-laminae follows the " $3 / 2$ power rule" (Bloomfield et al., 1987), we investigated whether the branching patterns of cells $\mathrm{W}-\mathrm{a}$ and $\mathrm{W}-\mathrm{b}$ follow this same rule. The $3 / 2$ power rule states that

$$
D^{3 / 2}=\sum_{i=1}^{n}\left(d_{i}\right)^{3 / 2}
$$

where $D$ is the diameter of a parent branch and $d_{i}$ values indicate the diameters of each daughter branch. The implication of such a branching pattern is that it maximizes current flow in both directions between synapses and the soma (see Bloomfield et al., 1987); it also means that a complexly branched dendritic structure can be collapsed into a single cylinder representing a
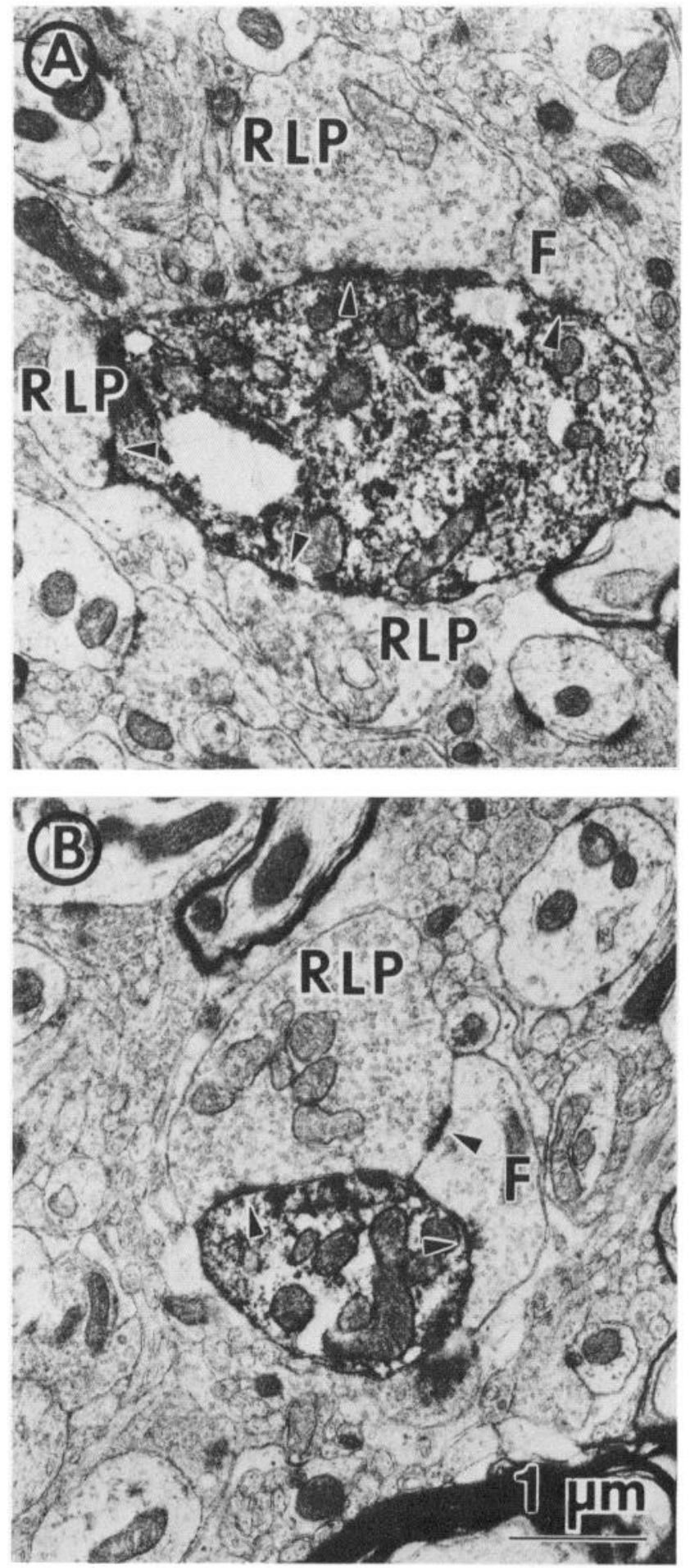

Figure 8. Electron micrographs of RLP terminals forming synapses (arrowheads) on dendritic segments of cell W-a. A, Three different RLP terminals contacting a labeled dendrite. $B$, A triad in which an RLP (retinal) terminal forms synapses (arrowheads) both on an HRP-labeled dendrite and on an $\mathrm{F}$ terminal which also contacts the identical labeled dendrite.

cable, and this greatly simplifies modeling of a cell's cable properties (Jack et al., 1975; Rall, 1977).

For cells W-a and W-b, each dendritic branching led to 2 daughter branches. We measured the values of $D$ and each $d_{i}$ 

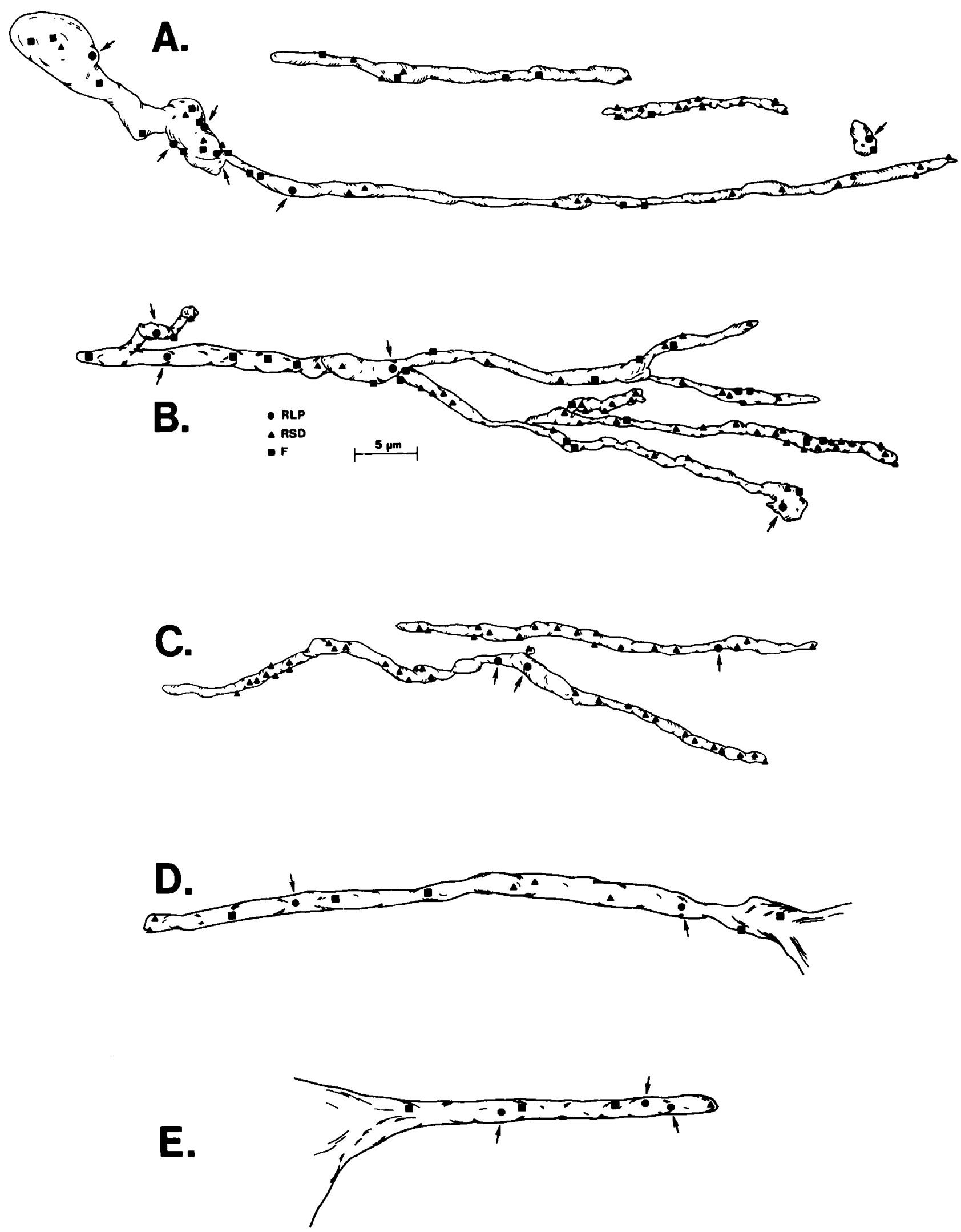

Figure 9. Selected reconstructions from serial electron micrographs of every dendritic segment of cell W-a $(A-E)$ that was found to be postsynaptic to RLP terminals (filled circles). On the examined portions of cell W-a (cf. Fig. 3), 18 RLP or retinal contacts, indicated by arrows, were identified. See Figure 3 for the locations of the dendritic segments represented here. Also indicated are synapses from F terminals (filled squares) and from RSD terminals (filled triangles). 


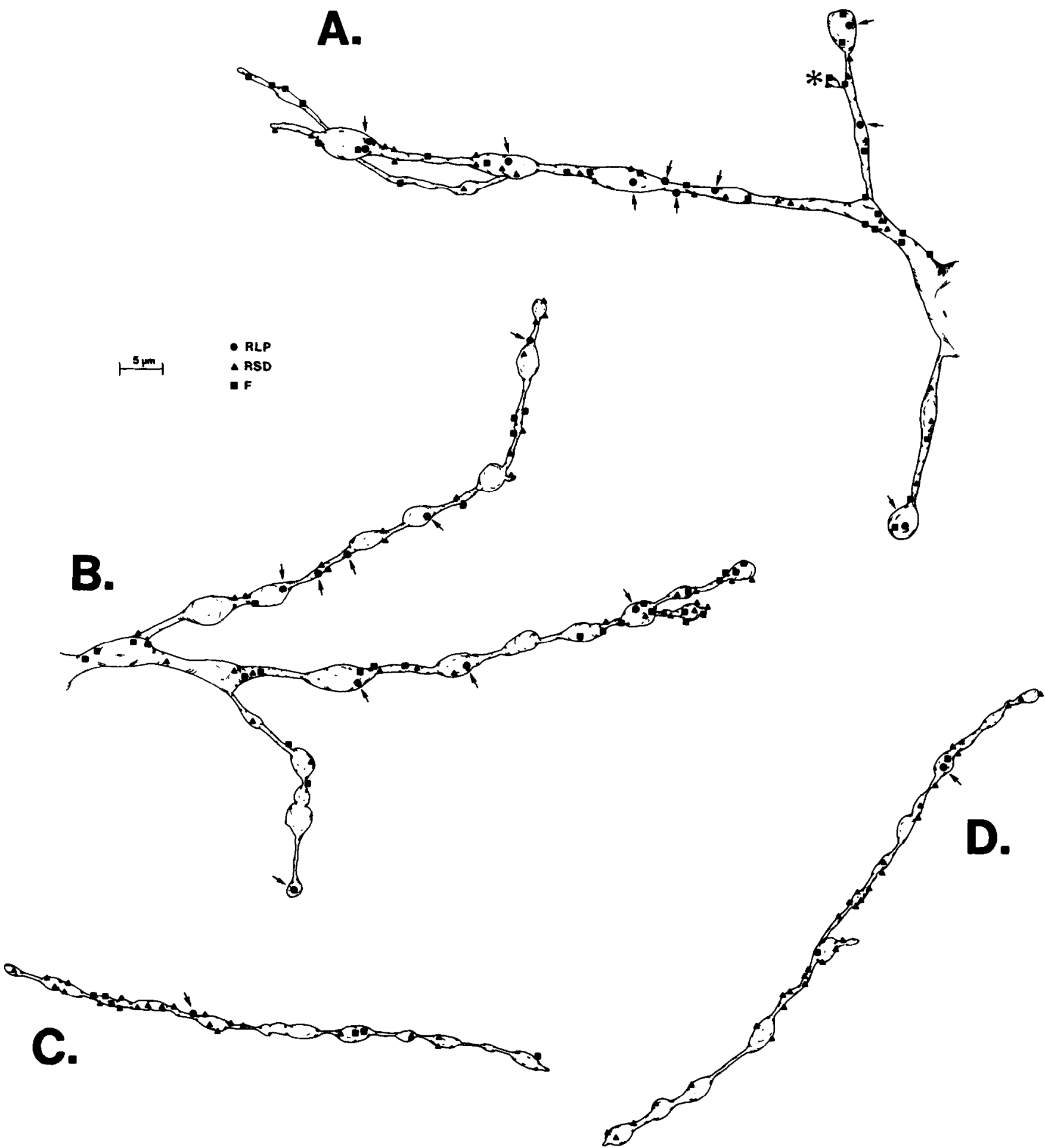

Figure 10. Selected reconstructions from serial electron micrographs of every dendritic segment of cell W-b $(A-D)$ that was found to be postsynaptic to RLP or retinal terminals; symbols as in Figure 9. On the examined portions of cell W-b (cf. Fig. 4), 20 RLP or retinal contacts, indicated by arrows, were identified. Note the lack of retinal input on the dendritic appendage in $A\left(^{*}\right)$. See Figure 4 for the locations of the dendritic segments represented here.

for 14 branch points, 7 from each cell. The measurements were made from serial reconstructions of the branch points with the electron microscope, and the branch points were chosen from proximal and distal locations so that a representative sample of diameters was included in our survey. Figure 16 shows that these $\mathrm{W}$-cells closely obey the $3 / 2$ power rule $(r=0.94 ; p<0.001)$.

\section{Discussion}

In the present study, we determined the pattern of synaptic input formed onto 2 physiologically identified W-cells in the parvocellular C-laminae of the cat's lateral geniculate nucleus. A comparison of our findings with analogous data previously published 


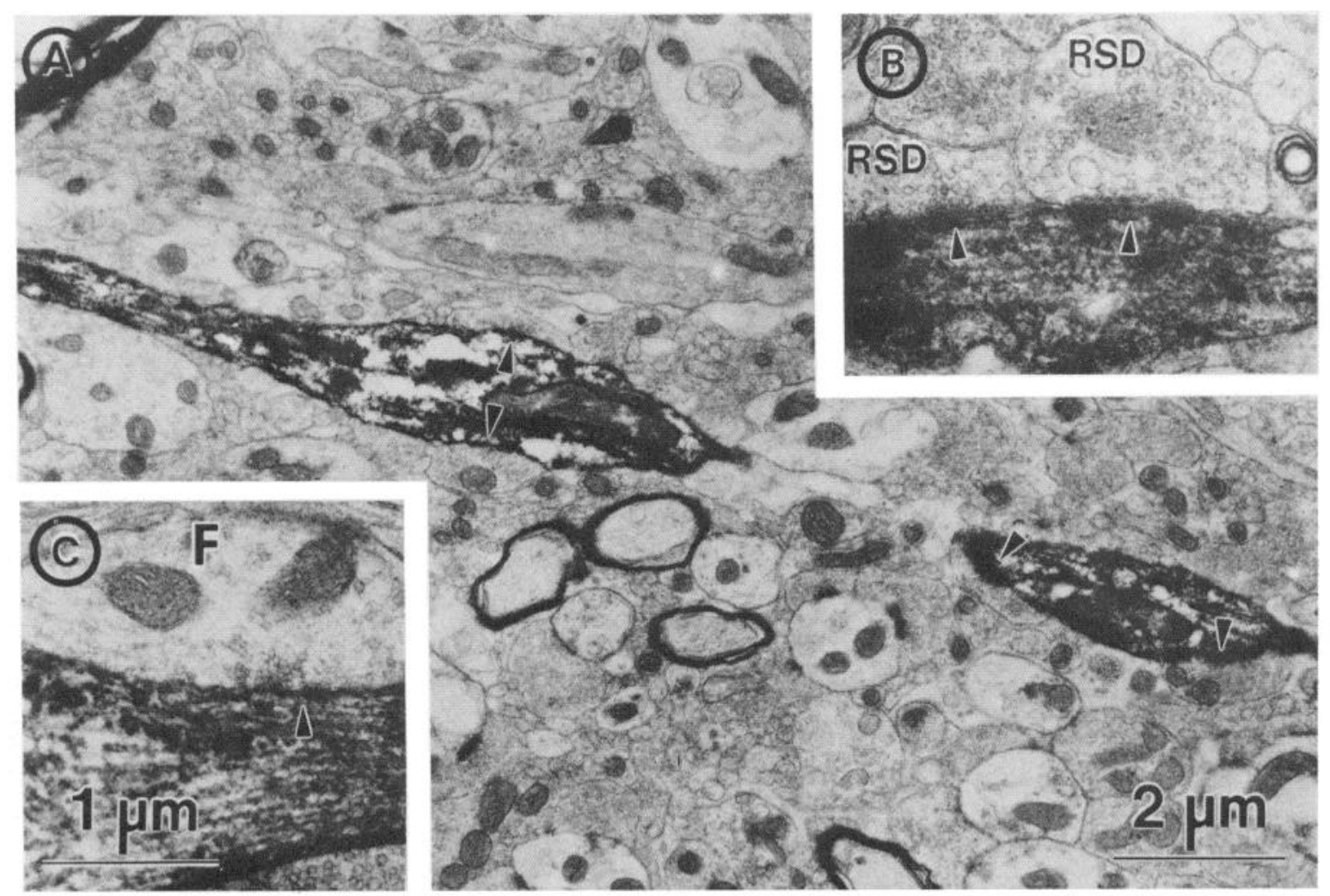

Figure 11. Electron micrographs showing RSD and F terminals forming synapses (arrowheads) on distal labeled dendrites of cell W-a. Note the varicose appearance of the dendritic shaft in $A$.

for geniculate X-and Y-cells (Wilson et al., 1984) suggests striking synaptic differences among the 3 neuronal classes. This, in turn, implies that functional differences among the W-, X-and $\mathrm{Y}$-cell pathways are not simply created in the retina and pas- sively relayed through the lateral geniculate nucleus to cortex; instead, differential geniculate circuitry enhances differences among the W-, X-, and Y-cell pathways. These and other related issues are discussed in further detail below.

\section{a.}
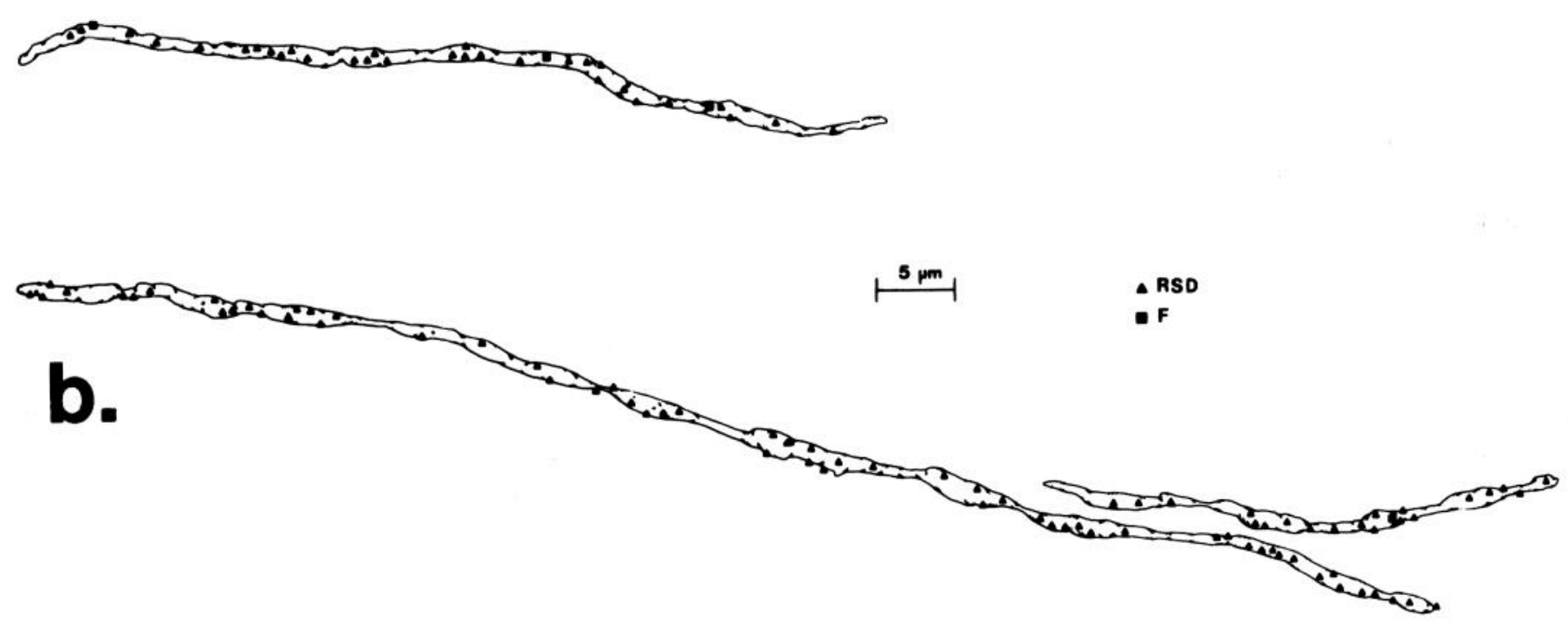

Figure 12. Selected reconstructions from serial electron micrographs of distal dendritic segments of cell W-a being contacted by RSD and F terminals (filled triangles and squares, respectively). Note the absence of contacts along several $5 \mu \mathrm{m}$ lengths of dendrite. See Figure 3 for locations of the dendritic segments represented here. 


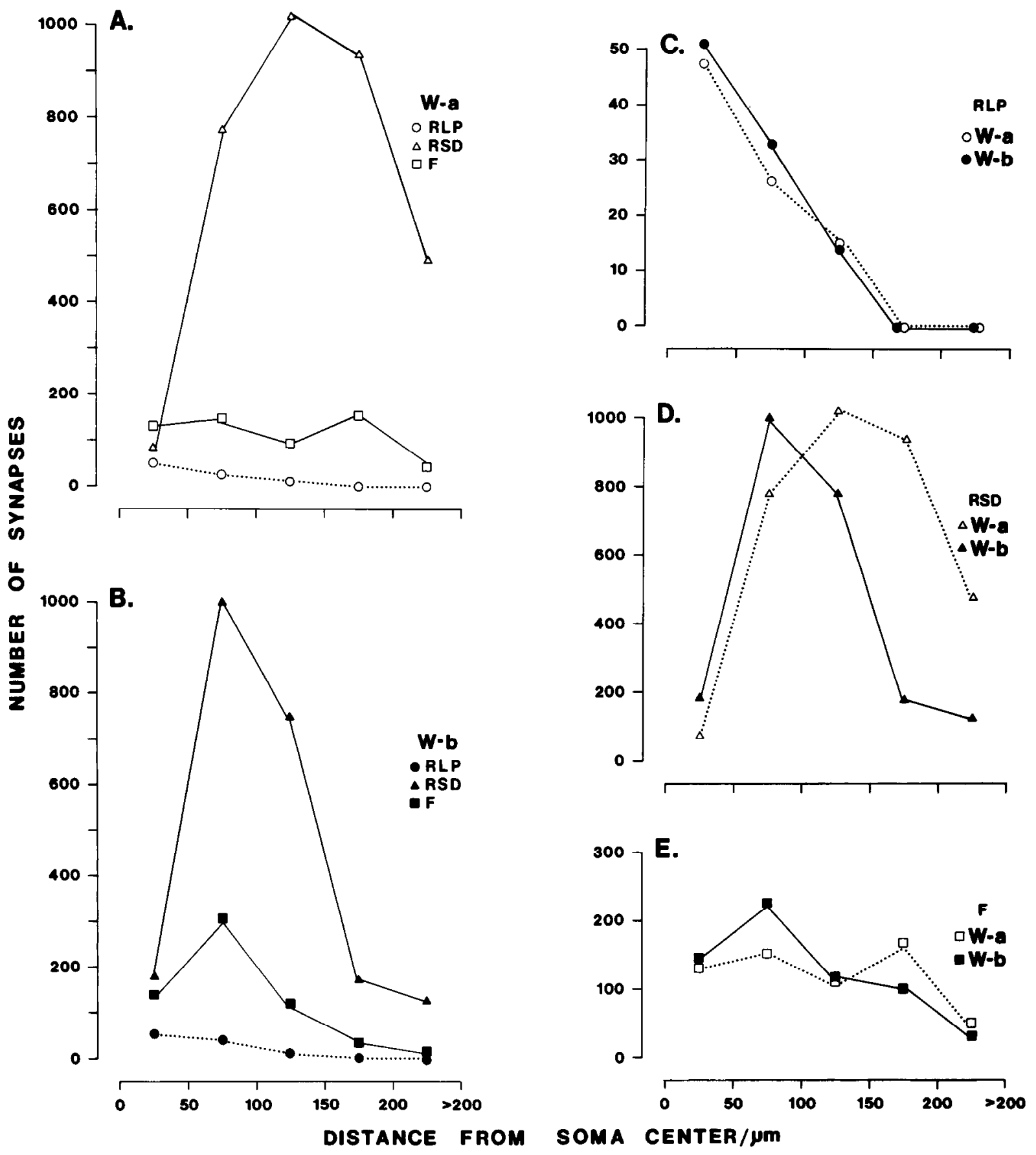

Figure 13. Graphs of total estimated number of synapses formed onto the dendrites of 2 W-cells (W-a and W-b) as a function of distance from the center of the soma. The abscissa gives the distance of the synapses (in $\mu \mathrm{m}$ ) from the center of the soma. The ordinate values are obtained by multiplying the actual synaptic counts within each $50 \mu \mathrm{m}$ zone taken from Table 3 by the percentage of dendritic length examined in that zone taken from Table $2 . A$ and $B$, Comparisons of numbers of synapses from all 3 terminal types for each cell. $C-E$, Separate comparisons between the $2 \mathrm{~W}$-cells for synapses from each terminal type.

\section{Limitations of the method}

The generality of our conclusions depends, in large part, on the reliability of our methods. In this regard, our greatest concern is the appropriateness of conclusions based on analyzing just 2 neurons. This concern has 2 related components: the appropriateness of extending our observations to the entire population of W-cells in the parvocellular C-laminae and the possibility that this neuronal population actually represents several distinct subtypes that cannot be appreciated from studying only 2 representatives.

Small data base. While our data base is quite large as measured in terms of numbers of synapses analyzed, we have only studied 2 geniculate neurons in detail. This is a concomitant of our time-consuming approach made necessary by serial reconstruction. For 2 reasons, we nonetheless feel that our observations are reasonably representative for the innervation patterns for geniculate W-cells of the parvocellular C-laminae. First, the 


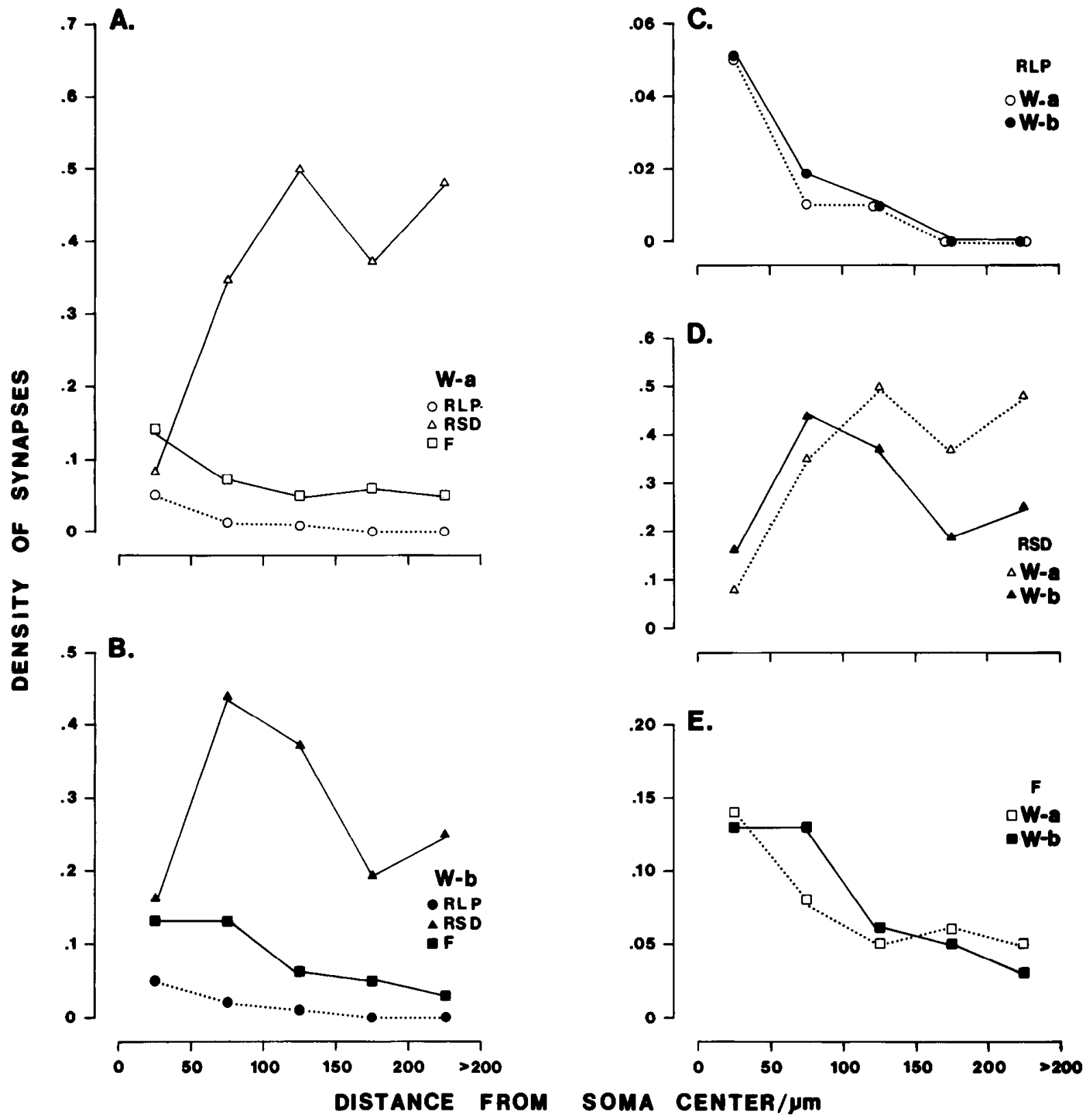

Figure 14. Graphs of the density of each synaptic type in number per micrometer as a function of distance from the center of the soma. The ordinate values were obtained as noted in Figure 13. $A$ and $B$, Comparisons for synapses from all 3 terminal types for each cell. $C-E$, Separate comparisons between the $2 \mathrm{~W}$-cells for synapses from each terminal type.

data we obtained from the 2 W-cells are internally consistent. The 2 neurons exhibited similar numbers and distributions of synapses from the various terminal types. Furthermore, different dendrites of each neuron also displayed similar patterns of synaptic input. Second, the relative percentage of synapses from each terminal type onto the labeled W-cells was $2-4 \%$ for RLP terminals, $75-80 \%$ for RSD terminals, and $20-25 \%$ for $F$ terminals. These values are remarkably close to those of a previous analysis of terminal varieties within comparable neuropil of the parvocellular C-laminae (see Table 3 of Guillery, 1969b; see also Guillery and Scott, 1971).

Subtypes of geniculate W-cells. The term "W-cell" has come to mean any retinal ganglion or geniculate cell that is neither an $\mathrm{X}$ - nor $\mathrm{Y}$-cell. There is increasing evidence that retinal W-cells include several distinct subtypes (e.g., Rowe and Stone,
1977; Leventhal et al., 1980, 1985; Rodieck and Brening, 1983; Stanford, 1987). Despite this, there is as yet no compelling evidence that geniculate $\mathrm{W}$-cells of the parvocellular C-laminae constitute more than a single class, albeit with considerable heterogeneity: The retinal axons innervating the parvocellular C-laminae seem to constitute a relatively homogeneous morphological group of retinal ganglion W-cells (Leventhal et al., 1980; Stanford, 1987), and there is no strong evidence from studies of the parvocellular C-laminae that more than a single class of W-cells inhabits this region (Cleland et al., 1975; Wilson et al., 1976; Sur and Sherman, 1982; Stanford et al., 1983). Consequently, while we cannot rule out the possibility that distinct types of geniculate W-cells were not sampled by us in the present study, there is no clear evidence that such subtypes exist.

We purposely chose 2 cells that differed along several param- 


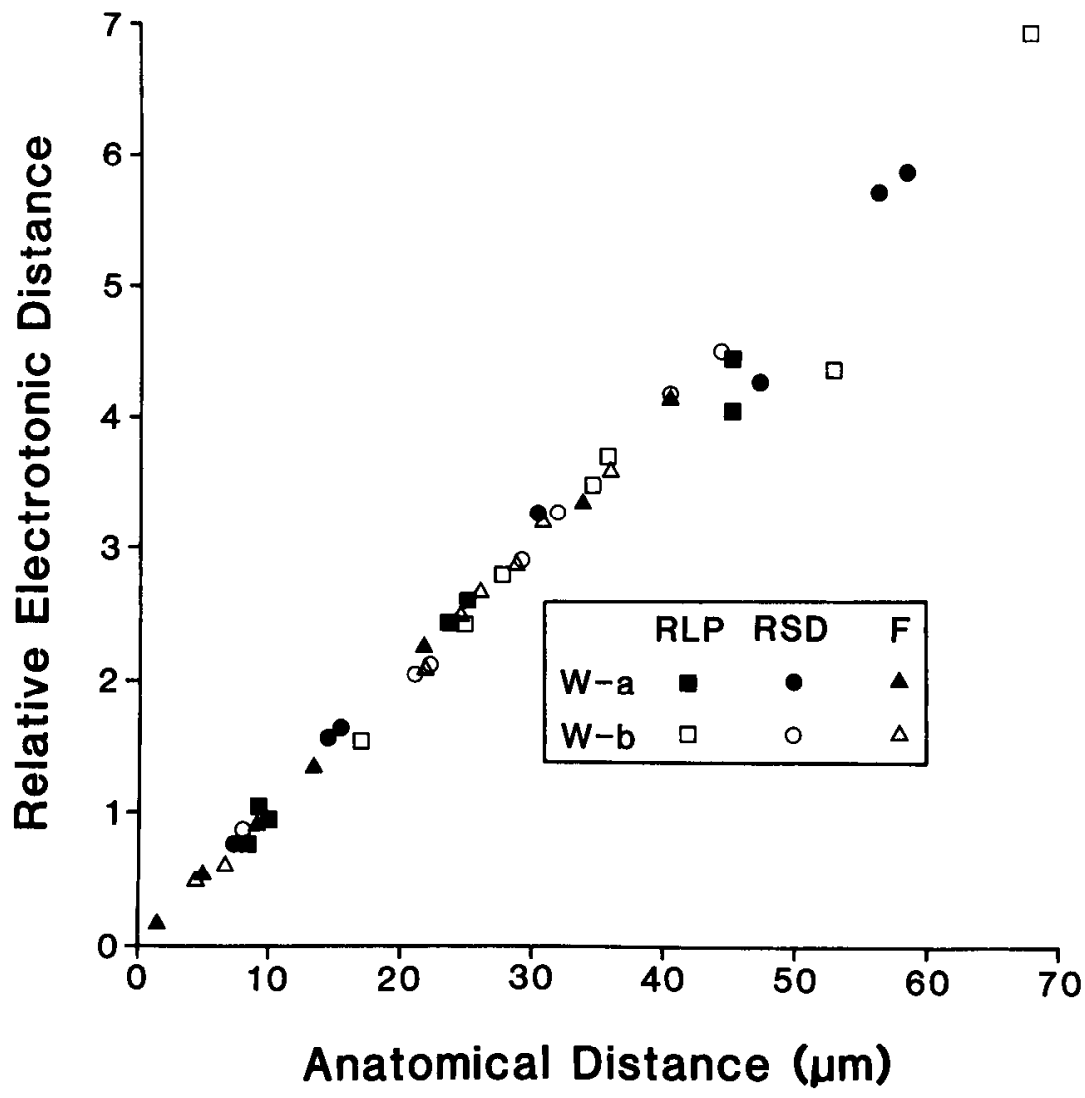

Figure 15. Graph showing the relationship between anatomical and clectrotonic distances for synapses from 42 terminals, 21 ( 7 of each terminal class) for each cell. The abscissa gives the actual anatomical distances from the synapse to the soma. The ordinate values were obtained by dividing the reconstructed dendrites into nontapering segments and dividing the length of each segment by the square root of its diameter. Electrotonic distance is the sum of all segmental electrotonic lengths from the synapse to the soma. eters so that our data were not limited to W-cells with a narrow range of features. Physiologically, the cells differ in response latency to optic chiasm latency (by roughly a factor of 2), in ocular dominance, in receptive field center type, and in responses to gratings. Morphologically, cell W-a displays much less dendritic beading than does cell W-b. Nonetheless, the range of physiological and morphological properties of these cells are entirely within the range noted previously for geniculate W-cells (Cleland et al., 1975; Wilson et al., 1976; Sur and Sherman, 1982; Stanford et al., 1983).

\section{Origin of synaptic input onto geniculate $W$-cells}

As is the case for the A-laminae, we found the morphological identification of terminal types forming synapses onto our labeled W-cells to be reasonably straightforward. These are the same types as previously described for the A-laminae (Guillery, 1969a, b), and this classification of terminals has been extended to the parvocellular C-laminae (Guillery, 1969a, b; Guillery and Scott, 1971; Mize et al., 1986). A question of obvious interest is the origin of these various terminal types.

For X-and Y-cells of the geniculate A-laminae, the sources of these terminals are reasonably well understood, although some uncertainties still exist. Here, the RLP terminals are isomorphic with retinal terminals (Guillery, 1969a; Robson and Mason, 1979; Hamos et al., 1987). Most of the RSD terminals are thought to derive from cortex (Guillery, 1969a; Robson, 1983), although some derive from axon collaterals of geniculate relay cells (Wilson et al., 1984; Van Horn, Hamos, and Sherman, unpublished observations), and some may reflect input from the brain-stem reticular formation (De Lima et al., 1985; Cucchiaro et al., 1986). The F terminals derive mainly from intrinsic interneurons and perigeniculate cells, both of which are GABAergic and presumed to be inhibitory (Fitzpatrick et al., 1984; Montero and Zempel, 1985). These terminals have been further subdivided based on their morphology and synaptology into $\mathrm{Fl}$

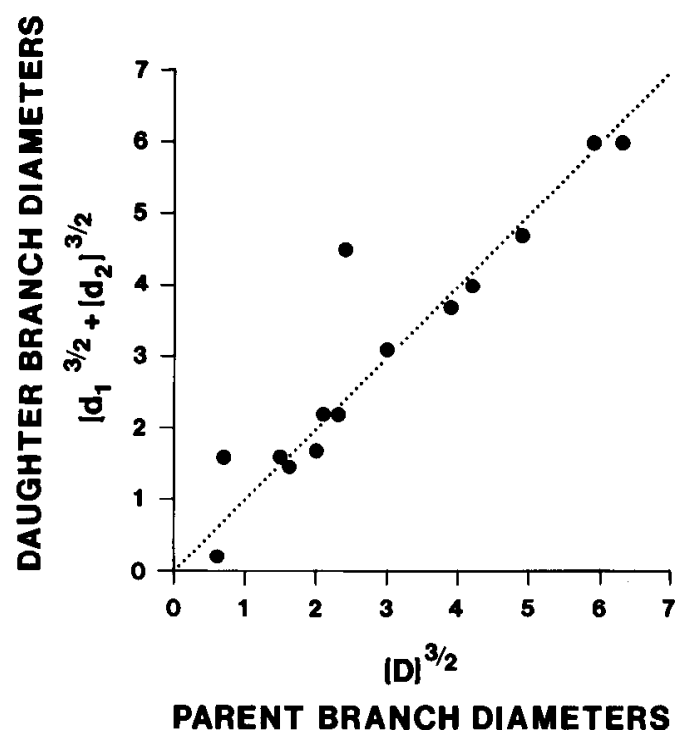

Figure 16. Graphs showing the $3 / 2$ power relationship among 14 parent dendrites and their daughter dendritic branches taken from these $\mathrm{W}$-cells (W-a and $\mathrm{W}-\mathrm{b})$. The abscissa gives the value in micrometers for the parent dendrite raised to the $3 / 2$ power. The ordinate gives the value in micrometers for the sum of the daughter dendritic branches raised to the $3 / 2$ power. The dotted line of slope 1 is drawn to indicate the locus of points expected if the values computed for the parent dendrites were equal to those computed for its daughter branches. 


\section{W-CELL}

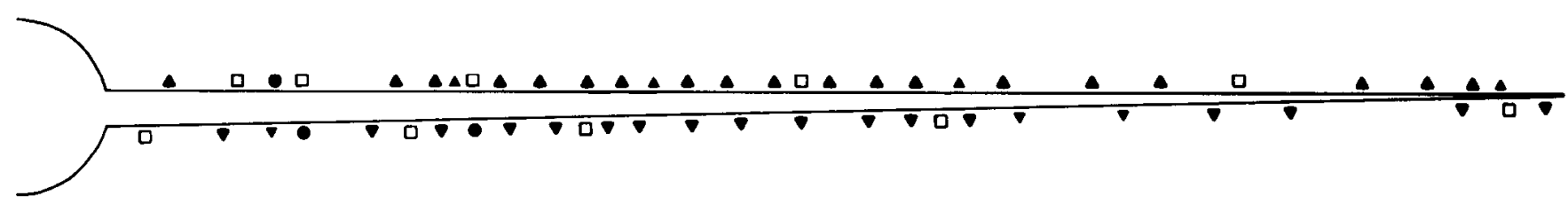

\section{$X$-CELL}
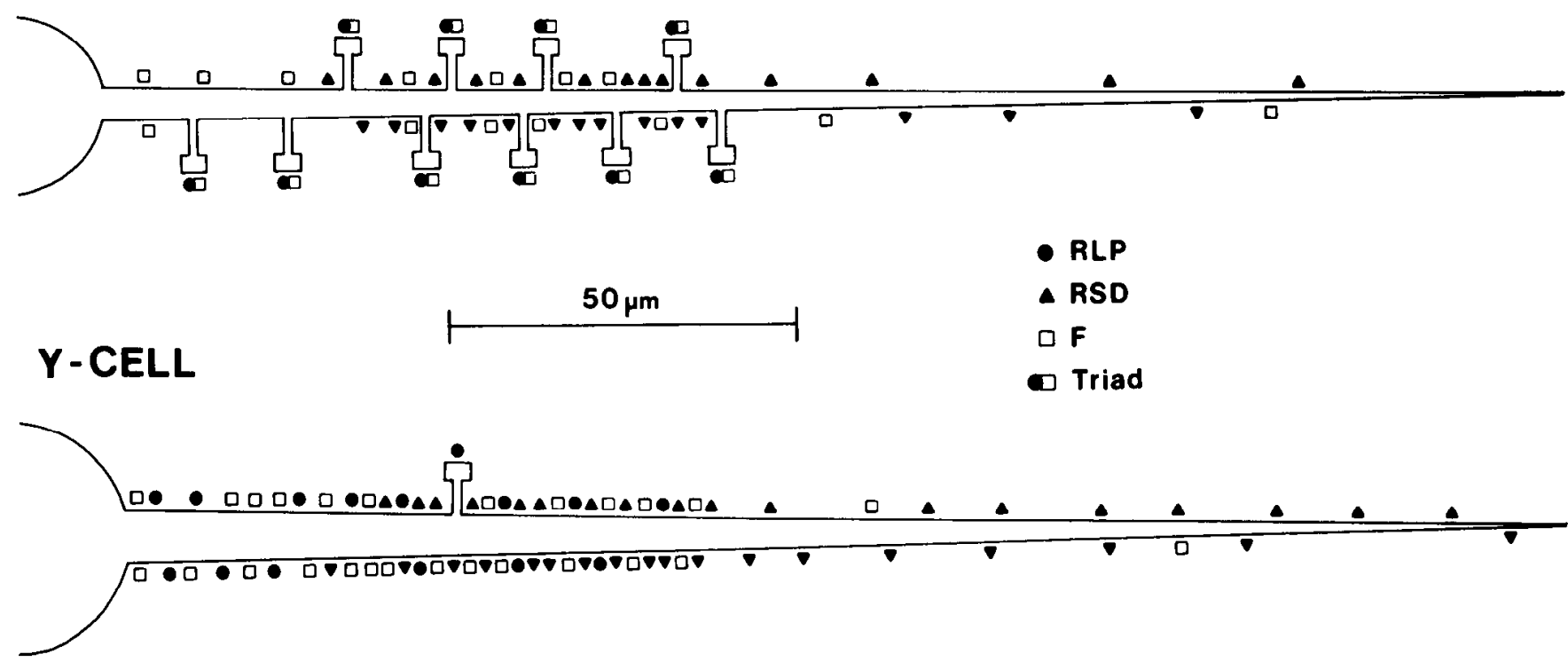

Figure 17. Schematic comparison of the relative number, distribution, and density of each synaptic type on geniculate W-, X-, and Y-cells. For each cell type, the synaptic relationships are compressed onto a single representative dendrite. The data for the X-and $Y$-cell are redrawn from Wilson et al. (1984).

and F2 types (Guillery, 1969a). Many F1 terminals derive from axons of perigeniculate cells (Cucchiaro et al., 1985) and are purely presynaptic to dendrites or to $\mathrm{F} 2$ terminals. Others seem to derive from axons of interneurons (our own unpublished observations) or from axons emanating from the brain-stem reticular formation (Cucchiaro et al., 1986). The F2 terminals derive from dendritic appendages of interneurons (Famiglietti and Peters, 1972; Hamos et al., 1985) and, as a prominent component of triads, are both presynaptic to dendrites and postsynaptic to other terminals.

With the exception of RLP terminals, which Mize et al. (1986) have recently demonstrated to be equivalent to retinal terminals, the source of inputs to W-cells of the parvocellular C-laminae are much less clear. Corticogeniculate input to these laminae is rather limited (Guillery, 1967; Updyke, 1975; Raczkowski and Rosenquist, 1980, 1983) and, as such, seems an unlikely candidate for the bulk of RSD terminals found there. Instead, Torrealba et al. (1981) described many terminals in laminae C2 and $\mathrm{C} 3$ that derive from the midbrain and that display morphology rather similar to RSD terminals. Other RSD terminals may be supplied by intrinsic collaterals of relay cells (cf. Stanford et al., 1983). Even less is known about the source of $F$ terminals. None of the axons from a limited sample of labeled perigenic- ulate cells has yet been traced beyond the A-laminae (Cucchiaro et al., 1985, and unpublished observations), so these cells are an unlikely source for many $F$ terminals in the parvocellular C-laminae. It is possible that other visual regions of the thalamic reticular nucleus, such as the region lying dorsal to the perigeniculate nucleus (Ahlsén et al., 1982), contribute $F$ terminals to these laminae. However, many interneurons seem to exist in the parvocellular C-laminae (Geisert, 1980; Hitchcock and Hickey, 1983; Fitzpatrick et al., 1984), and they are a likely source of $F$ terminals. However, much of the interneuron output in the A-laminae derives from dendritic appendages and takes the form of $F 2$ terminals engaged in synaptic triads, and such a terminal type is rare in the parvocellular C-laminae (see Results; see also Guillery and Scott, 1971; Mize et al., 1986). Therefore, while we can suggest plausible sources of nonretinal input to geniculate W-cells of the parvocellular C-laminae, this is still largely a matter of speculation.

Comparison of synaptic circuitry among geniculate $W-, X$-, and $Y$-cells

Figure 17 summarizes schematically some of the main features regarding distributions of synaptic inputs to geniculate W-, X-; and $\mathrm{Y}$-cells. The data for $\mathrm{X}$ - and $\mathrm{Y}$-cells are taken from the 
study of Wilson et al. (1984). We feel that the comparison between studies is justified, because we closely adhered to the techniques and protocols of Wilson et al. (1984) in our analysis of W-cells.

$\mathrm{X}$ - and $\mathrm{Y}$-cells have similar numbers both of total synaptic inputs (4000-5000) and of synaptic density along their dendrites (0.9-1.0 synapses $/ \mu \mathrm{m})$. They also have similar relative percentages of inputs from RLP (15-20\%), RSD (40-50\%), and F (25-30\%) terminals, with a concentration of synapses from RLP and $F$ terminals onto proximal dendrites. Here, similarities between input patterns end for X-and Y-cells. For X-cells, many of the $F$ terminals providing input are of the $F 2$ type and participate in synaptic triads involving most of the RLP input; these RLP/F2 triads usually innervate the X-cells via dendritic appendages. For $Y$-cells, most of the $F$ terminals providing synaptic inputs are of the F1 type, and they contact dendritic shafts alongside RLP inputs; synaptic triadic inputs are rare.

The observation in the present study that the 2 neurons sampled display remarkably similar patterns of synaptic input despite their physiological and morphological differences suggests the possibility that these input patterns are common to geniculate W-cells. If so, then the pattern of synaptic inputs to geniculate $\mathrm{W}$-cells of the parvocellular C-laminac is quite different on several grounds from that described above for either $\mathrm{X}$ - or $Y$-cells of the A-laminae. First, although the absolute number of synapses onto W-cells is just below that for $\mathrm{X}$ - and $\mathrm{Y}$-cells (i.e., $3000-4000$ vs $4000-5000$ ), the synaptic density is much lower (i.e., 0.4 synapses $/ \mu \mathrm{m}$ vs $0.9-1.0$ synapses $/ \mu \mathrm{m}$ ). This suggests that W-cells must have more extensive dendritic arbors than do X- or Y-cells, and this is precisely the conclusion reached by Stanford et al. (1983) in their light microscopic study of labeled W-, X-, and Y-cells in the lateral geniculate nucleus. Second, synapses from RLP terminals are much rarer by a factor of roughly 5 onto W-cells than onto X- or Y-cells. Third, the percentage of input from RSD terminals is much greater for W-cells (75-80\%) than for X- or Y-cells (40-50\%).

\section{Functional significance}

Geniculate $\mathrm{X}$ - and $\mathrm{Y}$-cells have essentially the same receptive field properties as do their retinal afferent inputs (Cleland et al., 1971; Hoffman et al., 1972; Bullier and Norton, 1979). Therefore, nonretinal inputs, which dominate innervation to these cells, must be employed to gate the relay of retinal signals to cortex along the X-and Y-cell pathways (reviewed in Sherman and Koch, 1986). Chief among the nonretinal inputs to X-and $\mathrm{Y}$-cells are synapses from RSD terminals, most of which are thought to reflect cortical innervation; thus, the cortex may play a prominent role in the gating of $\mathrm{X}$ - and $\mathrm{Y}$-cells.

As noted in the preceding section, a remarkable feature of the innervation patterns to the geniculate W-cells of this study is the paucity of direct retinal input and the relative dominance of input from RSD terminals. The lack of retinal inputs might partly explain the poor responsiveness of geniculate W-cells: They are difficult to activate via electrical stimulation of the optic chiasm, and they respond even more poorly and inconsistently to visual stimulation than do their retinal counterparts (cf. Cleland and Levick, 1974a, b; Sur and Sherman, 1982; Stanford et al., 1983; also our own unpublished observations). The even greater relative dominance by nonretinal input to the innervation of W-cells than to $\mathrm{X}$ - and $\mathrm{Y}$-cells suggests several possibilities. First, if analogous gating exists for W-cells, it must be relatively stronger than it is for $\mathrm{X}$ - and $\mathrm{Y}$-cells. Sccond, the nonretinal inputs may serve to elaborate novel receptive field properties in the W-cells, so that their receptive fields are significantly different from those of their retinal inputs. In this sense, circuitry within the C-laminae may function like that in retina or visual cortex to create more specific receptive properties. This latter possibility can be entertained for the simple reason that we have insufficient information about receptive field properties of geniculate W-cells vis-á-vis those of their retinal afferent inputs. Third, whatever the role of nonretinal inputs, their sources are largely different for W-cells than for Xor Y-cells. As noted above, RSD terminals provide the major nonretinal input to $\mathrm{X}$ - and $\mathrm{Y}$-cells, and this input is thought to derive largely from cortex. However, Torrealba et al. (1981) describe many terminals in the C-laminae that derive from the superior colliculus, and although these authors do not explicitly refer to these terminals as "RSD," they describe them as such. That is, like the RSD terminal of the present study (see also Guillery and Scott, 1971), many of those labeled from the superior colliculus have round vesicles, small profiles, dark mitochondria, and they form asymmetrical synapses (Torrealba et al., 1981). It is thus plausible that the midbrain may control W-cell response properties to an extent comparable to the control of X-and Y-cells from cortex.

\section{References}

Adams, J. C. (1977) Technical considerations on the use of horseradish peroxidase as a neuronal marker. Neuroscience 2 : 141-145.

Ahlsén, G., S. Lindström, and F.-S. Lo (1982) Functional distinction of perigeniculate and thalamic reticular neurons in the cat. Exp. Brain Res. 46: 118-126.

Bloomfield, S. A., J. E. Hamos, and S. M. Sherman (1987) Passive electrical properties of $\mathrm{X}$ - and Y-cells in the cat's lateral geniculate nucleus. J. Physiol. (Lond.) 383: 653-692.

Bullier, J., and T. T. Norton (1979) Comparison of receptive-field properties of $\mathrm{X}$ and $\mathrm{Y}$ ganglion cells with $\mathrm{X}$ and $\mathrm{Y}$ lateral geniculate cells in the cat. J. Neurophysiol 42: 274-291.

Cleland, B. G., and W. R. Levick (1974a) Brisk and sluggish concentrically organised ganglion cells in the cat's retina. J. Physiol. (Lond.) 240: $421-456$.

Cleland, B. G., and W. R. Levick (1974b) Properties of rarely encountered types of ganglion cells in the cat's retina and an overall classification. J. Physiol. (Lond.) 240: 457-492.

Cleland, B. G., M. W. Dubin, and W. R. Levick (1971) Sustained and transient neurones in the cat's retina and lateral geniculate nucleus. J. Physiol. (Lond.) 217: 473-496.

Cleland, B. G., R. Morstyn, H. G. Wagner, and W. R. Levick (1975) Long-latency retinal input to lateral geniculate neurones of the cat. Brain Res. 91: 306-313.

Cucchiaro, J. B., D. J. Uhlrich, J. E. Hamos, and S. M. Sherman (1985) Perigeniculate input to the cat's lateral geniculate nucleus: A light and electron microscopic study of single, HRP-filled cells. Soc. Neurosci. Abst. 11:231.

Cucchiaro, J. B., D. J. Uhlrich, and S. M. Sherman (1986) Brainstem innervation to the cat's lateral geniculate nucleus: An EM-immunohistochemical study using the tracer Phaseolus vulgaris leucoagglutinin (PIIA-L). Soc. Neurosci. Abstr. 12: 1037.

De Lima, A. D., V. M. Montero, and W. Singer (1985) The cholinergic innervation of the visual thalamus: An EM immunocytochemical study. Exp. Brain Res. 59: 206-212.

Famiglietti, E. V., and A. Peters (1972) The synaptic glomerulus and the intrinsic neurons in the dorsal lateral geniculate nucleus of the cat. J. Comp. Neurol. 144: 285-334.

Fitzpatrick, D., G. R. Penny, and D. E. Schmechel (1984) Glutamic acid decarboxlyase-immunoreactive neurons and terminals in the lateral geniculate nucleus of the cat. J. Neurosci. 4: 1809-1829.

Friedlander, M. J., C.-S. Lin, L. R. Stanford, and S. M. Sherman (1981) Morphology of functionally identified neurons in the lateral geniculate nucleus of the cat. J. Neurophysiol. 46: 80-129.

Geisert, E. E. (1980) Cortical projections of the lateral geniculate nucleus in the cat. J. Comp. Ncurol. 190: 793-812. 
Graybiel, A. M., and D. M. Berson (1980) Autoradiographic evidence for a projection from the pretectal nucleus of the optic tract to the dorsal lateral geniculate complex in the cat. Brain Res. 195: 1-12.

Guillery, R. W. (1967) Pattern of fiber degeneration in the dorsal lateral geniculate nucleus of the cat following lesions in the visual cortex. J. Comp. Neurol. 130: 197-222.

Guillery, R. W. (1969a) The organization of synaptic interconnections in the laminae of the dorsal lateral geniculate nucleus of the adult cat. Z. Zellforsch. Mikrosk. Anat. 96: 1-38.

Guillery, R. W. (1969b) A quantitative study of the synaptic interconnections in the dorsal lateral geniculate nucleus of the cat. $\mathrm{Z}$. Zellforsch. Mikrosk. Anat. 96: 39-48.

Guillery, R. W. (1971) Patterns of synaptic interconnections in the dorsal lateral geniculate nucleus of the cat and monkey: A brief review. Vision Res. Suppl. 3: 211-227.

Guillery, R. W., and G. L. Scott (1971) Observations on synaptic patterns in the dorsal lateral geniculate nucleus of the cat: The $\mathrm{C}$ laminae and the perikaryal synapses. Exp. Brain Res. 12: 182-203.

Hamos, J. E., S. C. Van Horn, D. Raczkowski, D. J. Uhlrich, and S. M. Sherman (1985) Synaptic connectivity of a local circuit neurone in lateral geniculate nucleus of the cat. Nature 317: 618-621.

Hamos, J. E., S. C. Van Horn, D. Raczkowski, and S. M. Sherman (1987) Synaptic circuits involving an individual retinogeniculate axon in the cat. J. Comp. Neurol. 259: 165-192.

Hickey, T. L., and R. W. Guillery (1974) An autoradiographic study of retinogeniculate pathways in the cat and the fox. J. Comp. Neurol. 156: 239-254.

Hitchcock, P. F., and T. L. Hickey (1983) Morphology of C-laminae neurons in the dorsal lateral geniculate nucleus of the cat: A Golgi impregnation study. J. Comp. Neurol. 220: 137-146.

Hoffmann, K.-P., J. Stone, and S. M. Sherman (1972) Relay of receptive-field properties in dorsal lateral geniculate nucleus of the cat. J. Neurophysiol. 35: 518-531.

Ide, L. (1982) The fine structure of the perigeniculate nucleus in the cat. J. Comp. Neurol 210: 317-334.

Jack, J. J. B., D. Noble, and R. W. Tsien (1975) Electrical Current Flow in Excitable Cells, Clarendon Press, Oxford.

Leventhal, A. G., J. Keens, and I. Tork (1980) The afferent ganglion cells and cortical projections of the retinal recepient zone (RRZ) of the cat's "pulvinar complex." J. Comp. Neurol. 194: 535-554.

Leventhal, A. G., R. W. Rodieck, and B. Dreher (1985) Central projections of cat retinal ganglion cells. J. Comp. Neurol. 237: 216-226.

Mize, R. R., R. F. Spencer, and L. H. Horner (1986) Quantitative comparisons of retinal synapses in the dorsal and ventral (parvocellular) C laminae of the cat dorsal lateral geniculate nucleus. J. Comp. Neurol. 248: 57-73.

Montero, V. M., and J. Zempel (1985) Evidence for two types of GABA-containing interneurons in the A-laminae of the cat lateral geniculate nucleus: A double-label HRP and GABA immunocytochemical study. Exp. Brain Res. 60: 603-609.

Peachey, L. D. (1958) Thin sections: A study of section thickness and physical distortion produced by microtomy. J. Biophys. Biochem. Cytol. 4: 237-242.

Raczkowski, D., and A. C. Rosenquist (1980) Connections of the parvocellular C laminae of the dorsal lateral geniculate nucleus with the visual cortex in the cat. Brain Res. 199: 447-451.

Raczkowski, D., and A. C. Rosenquist (1983) Conncctions of the multiple visual cortical areas with the lateral posterior-pulvinar complex and adjacent thalamic nuclei in the cat. J. Neurosci. 3: 19121942.

Raczkowski, D., J. E. Hamos, and S. M. Sherman (1984) Fine structural morphology of a physiologically identified W-cell in the cat's lateral geniculate nucleus. Soc. Neurosci. Abstr. 10: 297.

Rall, W. (1977) Core conductor theory and cable properties of neurons. In Handbook of Physiology, The Nervous System, Sect. 1, Vol. 1, Pt. 1, Chap. 3, pp. 39-97, Am. Physiol. Soc., Bethesda, MD.

Robson, J. A. (1983) The morphology of corticofugal axons to the dorsal lateral geniculate nucleus in the cat. J. Comp. Neurol. 216:89103.

Robson, J. A., and C. A. Mason (1979) The synaptic organization of terminals traced from individual labeled retino-geniculate axons in the cat. Neuroscience 4: 99-111.

Rodieck, R. W., and R. K. Brening (1983) Retinal ganglion cells: Types, genera, pathways and trans-species comparisons. Brain Behav. Evol. 23: 121-164.

Rowe, M. H., and J. Stone (1977) Naming of neurones. Brain Behav. Evol. 14: 181-216.

Sherman, S. M., and C. Koch (1986) The control of retinogeniculate transmission in the mammalian lateral geniculate nucleus. Exp. Brain Res. 63: 1-20.

Sherman, S. M., and P. D. Spear (1982) Organization of visual pathways in normal and visually deprived cats. Physiol. Rev. 62: 738855.

Stanford, L. R. (1987) W-cells in the cat retina: Correlated morphological and physiological evidence for two distinct classes. J. Neurophysiol. 57: 218-244.

Stanford, L. R., M. J. Friedlander, and S. M. Sherman (1983) Morphological and physiological properties of geniculate W-cells of the cat: A comparison with X-and Y-cells. J. Neurophysiol. 50: 582608.

Stone, J. (1983) Parallel Processing in the Visual System, Plenum, New York.

Sur, M., and S. M. Sherman (1982) Linear and nonlinear W-cells in C-laminae of the cat's lateral geniculate nucleus. J. Neurophysiol. 47 : 869-884.

Torrealba, F., G. D. Partlow, and R. W. Guillery (1981) Organization of the projection from the superior colliculus to the dorsal lateral geniculate nucleus of the cat. Neuroscience 6:1341-1360.

Updyke, B. V. (1975) The patterns of projection of cortical areas 17, 18 and 19 onto the laminae of the dorsal lateral geniculate nucleus in the cat. J. Comp. Neurol. 163: 377-396.

Wilson, J. R., M. J. Friedlander, and S. M. Sherman (1984) Fine structural morphology of identified X-and Y-cells in the cat's lateral geniculate nucleus. Proc. R. Soc. Lond. [Biol.] 221: 411-436.

Wilson, P. D., M. H. Rowe, and J. Stone (1976) Properties of relay cells in the cat's lateral geniculate nucleus. A comparison of W-cells with X- and Y-cells. J. Neurophysiol. 34: 1193-1209. 